Revista de Estudios Histórico-Jurídicos

[Sección historia del pensamiento político]

XLIII (Valparaíso, Chile, 2021)

[pp. 681-707]

\title{
LA DOCTRINA POLÍTICA DE BENEDICTO XV: UNA INTERPRETACIÓN ANTIMODERNA
}

[The political doctrine of Benedict XV: an anti-modern interpretation]

\author{
Julio Alvear Téllez* \\ Universidad del Desarrollo, Chile
}

\section{RESUMEN}

En los últimos quince años se ha despertado el interés por la figura de Benedicto XV. Su doctrina político-social ha vuelto a ser apreciada. Pero, por lo general, se le subordina a sus aspectos histórico contingentes, o, con cierto anacronismo, se le reduce a un antecedente de lo que solo viene a madurar después. En este artículo se analiza dicha doctrina en sí misma considerada, a partir de las fuentes directas, con especial atención a sus aspectos antimodernos, que completan el corpus político de León XIII y San Pío X en lo referente a la paz entre los pueblos, las bases del derecho de gentes, el fin último de las comunidades políticas, la relación entre la Iglesia y el Estado, y los supuestos morales de la vida pública.

$$
\text { Palabras Clave }
$$

Benedicto XV - Modernidad - Guerra-Paz.

\section{ABstract}

In the last fifteen years, interest in the figure of Benedict XV has been awakened. His political-social doctrine has been appreciated again. But generally it is subordinated to its contingent historical aspects, or, with a certain anachronism, it is reduced to an antecedent of what only comes to mature later. This article analyzes this doctrine itself, considered from direct sources, with special regard to its anti-modern aspects, which complete the political corpus of Leo XIII and Saint Pius X in relation to peace between peoples, the bases of the law of nations, the ultimate goal of political communities, the relationship between Church and State, and the moral assumptions of public life.

\section{KEY WORDS}

Benedict XV - Modernity - War Peace.

RECIBIDO el 30 de abril de 2020 y ACEPTADO el 1 de abril de 2021

* Doctor en Derecho y Doctor en Filosofía, Universidad Complutense de Madrid. Profesor titular de la Facultad de Derecho de la Universidad del Desarrollo. Correo: jalvear@udd.cl. ORCID: 0000-0002-2749-6072 


\section{ANTECEDENTES}

El Pontificado de Benedicto XV (1914-1922) fue marcado por la Primera Guerra Mundial; por sus causas, su desenvolvimiento y sus consecuencias. Desde el ángulo político, el principio liberal y laico se expande ante la caída de los dos grandes imperios europeos (el Imperio Austro-Húngaro y el Imperio alemán), mientras emerge el comunismo, como una posibilidad real de dominio de las naciones, a partir de la toma del Palacio de Invierno por los bolcheviques. Poco después, se inicia la andadura del fascismo, cuyo desabrochar el Pontífice no alcanzará a ver.

Quien en el mundo fuera Giacomo della Chiesa, tendrá que enfrentarse a todos estos problemas. Al hacerlo, explicitará elementos doctrinarios relevantes, sea en relación con la paz internacional, las bases del derecho de gentes, el fin último de las comunidades políticas, la relación entre el Estado y la Iglesia o los supuestos morales de la vida pública, que vienen a completar el corpus político-social de León XIII y San Pío X, en la línea de lo que se ha publicado en trabajos precedentes ${ }^{1}$.

Sobre Benedicto XV pesa un doble olvido. Primero, el recuerdo de su pontificado se vio condicionado por la memoria de la Gran Guerra. A pesar de la enorme impresión que esta conflagración produjo en los contemporáneos, pronto fue superada por una catástrofe peor: la Segunda Guerra Mundial. De tal modo que el atractivo por estudiar el pontificado del Papa della Chiesa, su enorme labor en favor de la paz y su deseo de construcción de un consorcio de naciones, se vio mermado por el interés que despertó la actividad de Pío XII frente a un acontecimiento histórico que reiteraba el desastre, pero con alcances mucho más terribles, complejos y universales. En este contexto, Benedicto XV fue relativamente olvidado hasta la elección de Benedicto XVI ${ }^{2}$.

Con motivo de la elección de Joseph Ratzinger, se hicieron explícitas referencias a su figura. En homenaje a él (y a San Benito de Nursia), el primero se impuso su nombre ${ }^{3}$. Este hecho renovó el interés por la figura de Giacomo della Chiesa y su pontificado, al menos si se juzgan las cosas desde la perspectiva de los estudios que se han publicado en los últimos años ${ }^{4}$. La mayor parte de dichos

${ }^{1}$ Alvear Téllez, Julio, El Corpus Politicum de León XIII. Una interpretación anti-moderna, en Revista de Estudios Histórico-Jurídicos, 40 (2018), pp. 445-472; ÉL mISMO, El Corpus politicum de San Pio X: una interpretación antimoderna, en Revista de Estudios Histórico-Jurídicos, 41 (2019), pp. 437-465.

${ }^{2}$ Probablemente las más entrañables biografías del pontífice se publicaron en los tiempos de Pío XII. Véase, Grope, Henry E., Benedict XV: The Pope of Peace (London, The Catholic Book Club, 1940) y Peters, Walter H., The Life of Benedict XV (Milwaukee, The Bruce Publishing, 1959). Pero no abundan durante dicho período, ni tampoco las monografías sobre su doctrina o su obra. Pese a todo, estos libros tienen el mérito de ser trabajos no contaminados por el prurito de m o d e r n i z a r al Pontífice a fin de adecuarlo a criterios que son posteriores a su mentalidad. Sigue ese mismo criterio, Chiron, Yves, Benoit XV. Le pape de la paix (París, Pierrin, 2014).

${ }^{3}$ Benedicto XVI, Audiencia General del 27 de abril de 2005, s/n; Benedicto XVI, Mensaje para la celebración de la XXXIX Jornada Mundial por la Paz, del 1 de enero de 2006, 2. El Papa Ratzinger hace expresa mención a la actividad en pro de la paz de su predecesor.

${ }^{4}$ El relativo olvido de Benedicto XV y la necesidad de su recuperación se denota en una interesante obra, Pollard, John, Benedict XV: The Unknown Pope and the Pursuit of Peace (London- 
estudios, con ser interesantísimos, no se centran en la doctrina de Benedicto $\mathrm{XV}$, en sí mismo considerada, sino en distintos aspectos de lo que en sentido amplio podríamos denominar su política en favor de la paz entre las naciones y sus correlatos ${ }^{5}$. Entre esos aspectos se encuentra su diplomacia, su actividad asistencial, su inclinación humanitaria, la apertura ecuménica y la preocupación por la buena formación del clero ${ }^{6}$.

New York, Bloomsbury, 2000), particularmente pp. 85-210, donde se examina su Pontificado. También, Hayward, Fernand, Un Pape Méconnu. Benoît XV (Tournai-Paris, Casterman, 1955). A este propósito, Doublet examina la historiografía sobre el pontífice hasta el año 2018. Refiere también a ese olvido histórico, Doublet, Nicholas Joseph, Benedict XV: A Historiographical Reading (Part 1), en Melita Theologica, 68/1 (2018), pp. 65-66.

${ }^{5}$ Una visión general en D’Abrizio, Mario, Benedetto XV , il papa della pace (Torino, Elledici, 2016), pp. 1-48; VINELli, Luigi, Benedetto XV costruttore di pace (Chiavari, Internòs Edizioni, 2016); Botrugno, Lorenzo (ed.), "Inutile strage". I cattolici e la Santa Sede nella Prima Guerra Mondiale (Ciudad del Vaticano, LEV, 2016); PAolini, Gabriele, Offensive di pace: la Santa Sede e la prima guerra mondiale (Florencia, Polistampa, 2008), con especial acento a las iniciativas humanitarias. La política pacífica de Benedicto XV mira siempre hacia el futuro, hacia una cooperación asociativa entre los pueblos. Primero entre los pueblos cristianos (el internacionalismo católico); luego entre los que no lo son, fundada en principios renovados del derecho de gentes, rumbo a una familia o liga de pueblos, como el Pontífice propone en Pacem Dei munus. En este sentido, es de suma utilidad estudiar las relaciones entre la Santa Sede y la Sociedad de las Naciones y sus antecedentes. Un análisis en los Archivos Secretos Vaticanos en Miranda, Americo, Santa Sede e Società delle Nazioni. Benedetto XV, Pio XI e il nuovo internazionalismo cattolico (Roma, Studium, 2013). En este punto, hay autores que destacan los aspectos p r o f é t i c o s de la acción del Pontífice. LetTerio, Mauro (a cura di), Benedetto XV. Profeta di pace in un mondo in crisi (Bologna, Minerva Edizioni, 2008), con un intento de identificación de las principales pautas del pontificado del Papa della Chiesa.

${ }^{6}$ Schnek, Juan y Cárcel Ortí, Vicente, Benedicto XV papa de la Paそ, (Valencia, Edicep, 2005), resalta cómo el pontificado de Benedicto XV supone una nueva etapa en las relaciones internacionales de la Santa Sede. Durante él se duplican las representaciones diplomáticas. En pp.245-251, las relaciones con Inglaterra, Francia, Holanda, Polonia, Portugal y Suiza. Por su parte, Regoli, Roberto y Valvo, Paolo, Tra Pio X e Benedetto XV: La diplomaria pontificia in Europa e America Latina nel 1914 (Roma, Studium, 2018) analizan las Relazioni presentadas a Benedicto XV sobre la situación de los países europeos, hispanoamericanos y de Palestina (pp. 21-226), con una evaluación general de la política vaticana, donde priman los intereses espirituales, sin perjuicio de la preocupación por los aspectos políticos, económicos y sociales (pp. 7-18). Hay que recordar que el Pontífice protestó con fuerza por el genocidio del pueblo armenio, en un contexto de indiferencia general de los pueblos europeos. También es interesante DOUBLET, Nicholas Joseph, A politcs of peace: The Congregation for Extraordinary Ecclesiastical Affairs during the pontificate of Benedict XV (1914-1922) (Roma, Studium, 2019), donde se estudia la diplomacia concordataria; la reivindicación de la libertas Ecclesiae y la cuestión romana; la actitud ante la Gran Guerra, con acento en la política humanitaria; los brotes nacionalistas en Rutenia, Bélgica, Polonia, Lituania, Irlanda y Checoslovaquia. El autor defiende documentadamente la postura de imparcialidad del Pontífice. Más particularmente, las relaciones con Alemania, Trinchese, Stefano, La repubblica di Weimar e la S. Sede tra Benedetto XV e Pio XI, 1919-1922 (Napoli, Edizioni Scientifiche Italiane, 1998); sobre Siria, Líbano y Palestina, DE Dreuzy, Agnes, The Holy See and the Emergence of the Modern Middle East: Benedict XV's Diplomacy in Greater Syria (1914-1922) (The Catholic University of America Press, 2016), en especial pp. 146-290, donde se analizan los años que van de 1917 a 1922, con un estudio de la encíclica Máximus illus y otros documentos, que junto con la política vaticana, suponen un cambio en la Santa Sede, en orden a una mayor aproximación a la cultura de aquellas tierras. Sobre las relaciones entre Benedicto XV y la Rusia 
Pero sigue cometiéndose un segundo olvido. Poco se insiste en su doctrina, en sí mismo considerada. Pareciera que no tiene el peso para ser apreciada sin subordinación completa a sus aspectos más contingentes. De sus aportes al magisterio político-social poco se habla. Y cuando se les aborda, se les ve con un cierto anacronismo, como un primer paso de lo que viene a madurar después, particularmente en el magisterio de Juan Pablo II y Benedicto XVI ${ }^{7}$.

Sin embargo, la figura de Benedicto XV merece ser analizada de una manera singular y autónoma. En este trabajo procuraremos estudiar la doctrina políticosocial del pontífice en sí mismo considerada. Para lo cual hemos de tener a la vista, aunque no podemos abocarnos a ello, los aspectos novedosos de su pontificado que colindan con nuestra temática ${ }^{8}$ o que permiten una mejor comprensión de

soviética, en ocasiones mal interpretadas, PETRACCHI, Giorgio, "La Missione pontificia di soccorso alla Russia (1921-1923)”, en VALENTE, Massimilliano (a cura di), Santa Sede e Russia da Leone XIII a Pio XII (Città del Vaticano, LEV, 2009), pp. 122-180. Para los vínculos con China, Giovagnoli, Agostino (a cura di), Roma e Pechino: La svolta extraeuropea di Benedetto XV, (Roma, Studium, 1999). Finalmente, es de mucho interés el trabajo de Zaldívar, Pablo, Benedicto XV. Un Pontificado marcado por la Gran Guerra (Pamplona, Eunsa, 2015), que trae un valioso análisis de la diplomacia humanitaria y las relaciones con los grandes gobernantes europeos. Es interesante, asimismo, el estudio de la piedad católica en el mundo germano, Houlinan, Patrick J., Catholicism and the Great War: Religion and Everyday Life in Germany and Austria-Hungary, 1914-1922 (Cambridge, Cambridge University Press, 2015).

${ }^{7}$ Mariano FAzo en su De Benedicto XV a Benedicto XVI (Madrid, Rialp, 2009) analiza el Pontificado del Papa della Chiesa como si fuera la etapa inaugural de aquella postura amigable de la Iglesia frente a las tendencias moderadas de la Modernidad, que madura en el Magisterio de Juan Pablo II y Benedicto XVI. Benedicto XV representaría los prolegómenos de la actitud positiva de los Papas ante el proceso de secularización, entendido como "desclericalización de la sociedad, como distinción entre el orden natural y el sobrenatural, entre Iglesia y Estado" (p.174). Lo que culminaría con la l a i c i d a d p o s i t i v a de Benedicto XVI. En una línea análoga, SсоттÀ, Antonio, Papa Benedetto XV. La Chiesa, la grande guerra, la pace (1914-1922) (Uomini e dottrine) (Roma, Storia e Letteratura, 2009). Ambas obras, por cierto, son de gran interes y muy bien estructuradas, pero, a nuestro juicio, no logran ceñirse a un Benedicto XV cuya doctrina pueda explicitarse desde sí mismo.

${ }^{8} \mathrm{La}$ actitud teórica y práctica de Benedicto XV con el modernismo, con las asociaciones católicas, con las asonadas revolucionarias (anarquismo, socialismo, comunismo), con el laicismo, con las víctimas del conflicto (sin distinción religiosa), suscitan diversos problemas que no podemos abordar en tan pocas páginas. Lo mismo puede decirse de su intento sincero de colocarse como árbitro de los pueblos, en un mundo que políticamente ya no se asienta en el principio cristiano. Una interpretación de éstas y otras temáticas, vinculadas a la singular personalidad del pontífice, se encuentra en diversos trabajos, que sería largo referir, y que han sido reunidos en Melloni, Alberto (Dir.), Benedetto XV. Papa Giacomo Della Chiesa nel mondo dell' "inutile strage" (Bologna, Il Mulino, 2017), 2 vols. Como complemento es muy útil ScOTTÀ, Papa Benedetto XV, cit (n. 7), pero contiene una interpretación de los ideales humanitarios y pacificadores del Pontífice quizás en exceso adecuados al catolicismo medioambiental de nuestros tiempos, que no son los del Papa della Chiesa. En contraposición puede verse Chiron, Yves, Benoit XV. Le pape de la paix, cit. (n. 2), quien da una interpretación de los puntos precedentes desde un ángulo más claramente vinculado a la mente del pontífice. El autor destaca, entre otros aspectos relevantes, el aprecio de Benedicto XV por el Imperio Austro-Húngaro, no en cuanto sujeto beligerante, sino como última potencia de la Cristiandad (p. 158). También lo destaca Rumi, Giorgio (a cura di), Benedetto XV e la pace, 1918 (Brescia, Morcelliana, 1990), pp. 37-47, en la correspondencia entre el Papa y Carlos I de Austria y IV de Hungría. En esta obra 
sus alcances, como la aproximación a la Sociedad de las Naciones, pese a sus orígenes nítidamente laicistas ${ }^{9}$, el esfuerzo por lograr la salida de la Santa Sede de su aislamiento internacional, la consciencia de que la guerra implica el fin del predominio histórico de Europa ${ }^{10}$, o la dispar actitud de los católicos ante la guerra ${ }^{11}$.

también se ausculta la visión de la Santa Sede respecto de Alemania, Francia, Italia, el Imperio Otomano, Estados Unidos, Inglaterra, Rusia y Polonia. Sobre la pervivencia de la guerra justa en un mundo donde la guerra parece ser siempre injusta, el interesante trabajo de ECHEVERRI, Alberto, Entre la "guerra justa" y "una inútil masacre": Benedicto XV, el papa desconocido, en Theologica Xaveriana, 70 (2020), edición en línea.

${ }^{9} \mathrm{La}$ Santa Sede estableció relaciones con los nuevos Estados surgidos de la Paz de Versalles, no obstante el Papa calificara el mapa europeo de ahí surgido como algo "elaborado por un loco". Chiron, Yves, Benoit XV. Le pape de la paix (cit. 2), p. 249. Su propósito no era ayudar al diseño de una futura Europa laica, sino pacificar a los pueblos atormentados por el conflicto. De ahí que en la Alocución del 21 de noviembre de 1921 manifestara su intención de establecer vínculos diplomáticos con los nuevos Estados. La actitud incansable de benevolencia de Benedicto XV no fue pagada con la misma moneda. Pese a su ayuda humanitaria, a su diplomacia destinada a evitar la expansión de la guerra, a su inducción a los beligerantes para que se sienten en la mesa de negociaciones, a sus inumerables iniciativas asistenciales (asistencia a huérfanos, práctica de derecho de gentes para prisioneros, búsquedas de personas desaparecidas, provisión de alimentos, etc.), el Papa fue excluido formalmente de las negociaciones de paz en el Congreso de Versalles (aunque se permitió un observador diplomático de la Santa Sede) y no fue invitado a ser miembro de la Sociedad de las Naciones. JeDin, Hubert y Repgen, Konrad, Manual de bistoria de la Iglesia (Barcelona, Herder, 1984), IX, pp. 76-91. El pontífice no fue neutral, sino imparcial, pues no pensaba posicionarse por encima del conflicto, sino tratar de intervenir directamente en él, aduciendo razones de caridad, de justicia y para cuidar los intereses de la Iglesia. Sin embargo, la propaganda nacionalista arrastró a los católicos de ambos bandos, por lo que fue muy difícil resguardar el carácter supranacional del Papado. Siempre apeló a una paz con negociación satisfactoria, no una a paz impuesta por los vencedores. La exclusión de Benedicto XV dio como fruto unos tratados cuyas cláusulas no aseguraron la paz, y que, además, fueron contrarios a los intereses de la Cristiandad. Aún así, trató de influir en la Sociedad de las Naciones, a fin de que fuera reconocido el principio de arbitraje del Papado. Rops, Daniel, Historia de la Iglesia de Cristo (Madrid, Caralt - Fayard, 1971), XII, pp. 219-226. En este punto, hay que recordar que las propuestas de paz del Pontífice fueron más realistas y más equitativas que las de Versalles. LlorCa, Bernardino; García-Villoslada, Ricardo et al, Historia de la Iglesia (Madrid, BAC, 1951), IV, p. 450.

${ }^{10}$ VARnier, Giovanni B., Benedetto XV e i problemi della society contemporanea, en LETTERIO, Mauro (a cura di), Benedetto XV. Profeta di pace in un mondo in crisi (Bologna, Minerva Edizioni, 2008), pp. 327-343.

${ }^{11}$ Benedicto XV realizó una encomiable labor con las naciones católicas -particularmente con sus gobernantes y los respectivos episcopados-a fin de que se deponga la pasión nacionalista, que en la época, inficionaba las relaciones internacionales. Como se sabe, no tuvo éxito. El caso italiano es particularmente decidor. Dos estudios dan cuenta de ello. Ciriello, Caterina, Benedetto XV, la guerra e le posizioni dei vescovi italiani, en Anuario de historia de la Iglesia, 23 (2014), pp. 41-60; y Painno, María, La preghiera e la grande guerra. Benedetto XV e la nazionalizzazione del culto in Italia (Pisa, Pacini Editore, 2017). También, VArnier, Giovanni B., "Una guerra ingiusta". La Santa Sede e l'Italia tra neutralità e intervento (1914-1915), en Anuario de Historia de la Iglesia, 23 (2014), pp. 17-39. En este último trabajo se puede ver cómo en muchos lugares la oración cristiana perdió su sentido universal y se transformó en un instrumento espiritual para reforzar el nacionalismo partisano, en oposición a los principios comunitarios de la Cristiandad, cuyo máximo garante era el Papa. En esta misma línea, Rossins, Giuseppe (a cura di), Benedetto XV, $i$ cattolici e la prima guerra mondiale (Roma, Edizione 5 Lune, 1963), donde se estudia la actividad 


\section{Un PROGRAMA PARA LA PAZ VERDADERA y LA JUSTICIA ENTRE LOS PUEblos}

\section{Presupuestos}

Iniciamos el análisis con la encíclica $A d$ beatissimi, que sirve de entronización y programa al pontificado del Papa della Chiesa, y continuamos con otros documentos hasta llegar a los que señalan el término de su magisterio, en los que se advierte, con sorprendente clarividencia, que otra gran guerra se aproxima, develando las causas.

No es fácil comprender el programa de Benedicto XV sin caer en anacronismos que alteren la sustancia de su doctrina. La paz y la justicia internacional tienen hoy unas vetas culturales que las condicionan y que no corresponden exactamente a las que estaban presentes en las dos primeras décadas del siglo XX. Cesar las hostilidades mediante la negociación y reorganizar la Europa del futuro y el mundo de la posguerra, se trazaba en un contexto histórico y en torno a ideales diversos a los que hoy consideramos. Ello se daba tanto en la Iglesia, como en los círculos laicos.

Benedicto XV, por más pragmático que fuera, aún pensaba en la Cristiandad, como ideal de la sociedad terrena. Ello queda bastante claro en la encíclica Pacem Dei munus y otros documentos.

A la sazón, los gobiernos de las potencias beligerantes occidentales también tenían otros proyectos. Si la guerra habría de terminar, la reorganización del mundo se haría de acuerdo a los conceptos humanitarios, filantrópicos, propios de la cultura laica, impregnada de optimismo cientificista y evolucionista, tan bien representado en la figura de Wodroow Wilson ${ }^{12}$. La clave del nuevo edificio será, a fines de la guerra, la Sociedad de las Naciones, un vasto consejo de los pueblos del mundo, dispuestos a resolver las cuestiones internacionales a través del voto, según criterios de justicia y de equidad, a cuyas razones todos se allanarán ${ }^{13}$.

Se sabía, de alguna manera, que era la Iglesia Católica quien había cambiado el

diplomática de Benedicto XV a través de los archivos de la Secretaría de Estado y la postura de los católicos no italianos frente a la Gran Guerra, con particular atención a Alemania, Austria, Hungría, Europa oriental, EEUU, América Latina, Francia, Bélgica e Inglaterra. Sobre los católicos franceses, es sintomático el caso del célebre teólogo dominico, fiel a Roma, Antonin Sertillanges, ChIron, Yves, Benoit XV. Le pape de la paix, cit. (n. 2), pp. 223-226. Con los Estados, la relación fue más compleja aún. Los gobiernos de Francia e Italia, impulsados por el laicismo masónico, de moda a la sazón en ciertas elites descristianizadas, no querían al Papa como mediador, pues implicaba, de algún modo, reconocer su autoridad moral. El gobierno italiano le denominó “Maledicto XV”, mientras Georges Clemenceau hizo célebre la expresión "Pape boche". Por motivos puramente nacionalistas, en el mundo germánico Erich Ludendorff le llamó "Französische Papst".

${ }^{12}$ Sobre el perfil biográfico e ideológico de Wilson, CoOper Jr., John Milton, Reconsidering Woodrow Wilson: Progressivism, Internationalism, War, and Peace (Johns Hopkins University Press, 2008). Sobre Wilson y la Sociedad de las Naciones, Cooper Jr., John Milton, Breaking the Heart of the World: Woodrow Wilson and the Fight for the League of Nations (New York, Cambridge University Press, 2001).

${ }^{13}$ Sobre la Sociedad de las Naciones, Walters, Francis Paul, A History of the League of Nations (New York, Oxford University Press, 1952), 2 vols.; Marbeau, Michel, La Société des Nations (Paris, Presses Universitaires de France, 2001); Ostrower, Gary, The League of Nations: 
paradigma de la pax romana, que era un modelo de dominación, por el paradigma de un consorcio entre naciones fundado en la común justicia entre los pueblos, hermanados por unas mismas creencias.

Pero ahora las creencias de los gobiernos no eran las cristianas, al menos en su sentido fuerte. Además, el sueño de una justicia entre los pueblos, arbitrada por el Papa, se extingía desde hace un siglo, con el término de lo que representaba el Sacro Imperio y el fin definitivo del Imperio Austro-Húngaro ${ }^{14}$. Pero, por otro lado, también la política del equilibrio europeo fundada no en la paz, sino en el mutuo interés, en la mutua codicia y en la recíproca capacidad para armarse, había demostrado su fracaso precisamente con la Gran Guerra ${ }^{15}$.

Después de la Guerra, parecía volver el ideal medieval de la justicia entre los pueblos, pero con revestimiento ideológico moderno, de acuerdo a los ideales democráticos del siglo XX. Se esperaba que fuera posible "restaurar una superestructura de pueblos. Pero el Sacro Imperio era monárquico y cristiano. Y la Revolución Francesa había republicanizado y laicizado el mundo. La Sociedad de las Naciones, hecha a imagen de la nueva Europa, republicana y laica, sería un organismo de constitución republicana y laica", destinado a realizar el ideal representado por el Sacro Imperio, en un nuevo molde, que de partida no podía admitir el concurso del Pontificado Romano ${ }^{16}$.

Benedicto XV midió bien los alcances de este proyecto. Rechazó el laicismo como base duradera de la paz entre los pueblos. Pero aprobó algunos objetivos, en la medida que se conciliaban con el derecho de gentes ${ }^{17}$.

Analicemos a continuación la doctrina del Pontífice.

\section{La etiología de la Gran Guerra}

Ad beatissimi ${ }^{18}$ señala la etiología religiosa, moral y política de la Gran Guerra,

From 1919-1929 (New York, Avery Publishing Group, 1996); Borowy, Iris, Coming to terms with world health: the League of Nations Health Organisation 1921-1946 (New York, Peter Lang, 2009).

${ }^{14}$ Sobre el Imperio Austro-Húngaro, y lo que representó como heredero del Sacro-Imperio, Jonhston, William (2009), El genio austrohúngaro. Historia social e intelectual (1848-1938) (Oviedo, KRK Ediciones, 2009). Sobre la monarquía de los Austria, BÉRENGER, Jean, Histoire de l'empire des Habsbourg, 1273-1918 (París, Fayard, 1990). Sobre la voluntad, en paralelo, de acabar con dicho imperio por parte de las fuerzas laico-republicanas y masónicas, FEjTÖ, François, Requiem pour un empire défunt. Histoire de la destruction de l'Autriche-Hongrie (Paris, Lieu Commun, 1998). Sobre el fin del imperio y su luz que se extingue, BLED, Jean-Paul, L'agonie d'une monarchie. Autriche-Hongrie 1914-1920 (París, Tallandier, 2014), pp. 429-443. Una síntesis en SCHIAvon, L'Autriche-Hongrie dans la Première Guerre mondiale. La fin d'un Empire (París, Soteca, 2011).

${ }^{15}$ Sobre el sistema de equilibrio europeo, Kissinger, Hebry, El orden mundial (Barcelona, Debate, 2016), pp. 59-103.

${ }^{16}$ Corrêa de Oliveira, Plinio, Uma experiência que não deve ser esquecida, en Legionário, 599, 30 de janeiro de 1944.

${ }^{17}$ Sobre este punto, es interesante SHINe, Cormac, Papal Diplomacy by Proxy? Catholic Internationalism at the League of Nations' International Committee on Intellectual Cooperation, en The Journal of Ecclesiastical History, 29/4 (2018), pp. 785-805.

${ }^{18}$ Benedicto XV, Encíclica Ad beatissimi del 1 de noviembre de 1914, sobre la guerra mundial y sus causas; en AAS., 6 (1914), pp. 615-629. Para la traducción y numeración utilizamos la versión digital del Centro de Estudios y Documentación Padre Hurtado. 
análisis completado, una vez concluida ésta, por Pacem Dei y Bonum sane et salutare. A nuestros efectos, nos interesa identificar las siguientes ideas centrales:

- El espíritu de la guerra se encuentra en casi todas partes. La Europa opulenta choca entre sí sembrando sangre y ruinas universales. Olvidó por completo los lazos de hermandad que liga a los pueblos cristianos. Lazos de creencias primarias y de vivencias universales, cuya ausencia hace posible una lucha tan destructiva ${ }^{19}$.

- La causa última de la guerra es de naturaleza civilizatoria, cultural y religiosa: el proceso de defección de la fe cristiana por parte de los Estados y las sociedades. El abandono de la ley cristiana ha dejado al orden político y social europeo sin su sustento comunitario más sólido, y amenaza la perviviencia de la sociedad misma ${ }^{20}$.

Llama la atención la relevancia que cobra el hecho de que el cristianismo haya sido abandonado como idea rectora por los gobiernos y regímenes políticos estatales ("etenim ex quo christianae sapientiae praecepta atque instituta observari desita sunt in disciplina rei publicae, cum stabilitatem tranquillitatemque ordinis illa ipsa continerent”, precisa). El abandono del principio cristiano produce otras tantas causas subsecuentes, que son las que originan la guerra de un manera más próxima e inmediata. El Pontífice habla de cuatro causas ("quatuor capitibus causas"), las que pueden rotularse del modo que sigue:

a. Causa religiosa-moral: ausencia de caridad cristiana en las relaciones internacionales, en las relaciones al interior de los Estados y en las relaciones privadas. En éstas prima el egoísmo y el materialismo. En las precedentes, el odio o la malevolencia engendrada por las diferencias de clases, de razas y de fronteras. La fraternidad universal, prometida por los ideales humanitarios modernos, no se ha podido sustentar sin la caridad cristiana ${ }^{21}$.

${ }^{19}$ Es interesante seguir las propias palabras del pontífice: "Parece que, en realidad, han llegado aquellos días de los que Jesucristo profetizó: 'Oiréis hablar de guerra y de rumores de guerra [...] Se levantará nación contra nación’. El tristísimo fantasma de la guerra domina por doquier, y apenas hay otro asunto que ocupe los pensamientos de los hombres. Poderosas y opulentas son las naciones que pelean; por lo cual ¿qué extraño es que, bien provistas de los horrorosos medios que en nuestros tiempos el arte militar ha inventado, se esfuercen en destruirse mutuamente con refinada crueldad? No tienen, por eso, límite ni las ruinas, ni la mortandad; cada día la tierra se empapa con nueva sangre y se llena de muertos y heridos. ¿Quién diría que los que así se combaten tienen un mismo origen, participan de una misma naturaleza, y pertenecen a la misma sociedad humana? ¿Quién les reconocería como hermanos, hijos de un mismo Padre que está en los cielos? Y mientras que de una y ora parte formidables ejércitos pelean furiosamente, las naciones, las familias, los individuos sufren los dolores y miserias que, como triste cortejo, siguen a la guerra. Aumenta sin medida, de día en día, el número de viudas y de huérfanos; se paraliza, por la interrupción de las comunicaciones, el comercio; están abandonados los campos y suspendidas las artes; se encuentran en la estrechez los ricos, en la miseria los pobres, en el luto todos". Benedicto XV, Ad beatissimi, cit. (n. 18), 2.

20 "Desde que se han dejado de aplicar en el gobierno de los Estados la norma y las prácticas de la sabiduría cristiana, que garantizaban la estabilidad y la tranquilidad del orden, comenzaron, como no podía menos de suceder, a vacilar sus cimientos las naciones y a producirse tal cambio en las ideas y en las costumbres, que si Dios no lo remedia pronto, parece ya inminente la destrucción de la sociedad humana [...] Todos, por lo tanto, debemos esforzarnos en que por completo desaparezcan, restableciendo los principios del cristianismo, si de veras se intenta poner paz y orden en los intereses comunes”. Ibíd., 4.

${ }^{21}$ Ibíd., 5 y 6. 
b. Causa política: el liberalismo ha llevado al desprecio del principio de autoridad en su sentido más profundo. Aplicando la doctrina política de sus antecesores, Benedicto XV sostiene que el derecho público moderno, al desacralizar el poder político y atribuirlo a la pura voluntad humana, ha quebrado el legítimo fundamento de la obediencia política. Cuestión que se ahonda con el dogma de la soberanía popular (que niega el origen divino del poder) y el reconocimiento de las libertades modernas, calificadas como "el inmoderado deseo de libertad", que conducen a horadar el principio de autoridad en el ámbito social y familiar ${ }^{22}$. En este punto tan esencial, se reitera la necesidad de que la fe y la moral cristiana vuelvan a impregnar el orden político y social ${ }^{23}$.

c. Causa social: A la ruptura de los vínculos de cohesión política se agrega la lucha de clases avivada por la revolución socialista y su utopía de un mundo igualitario. Benedicto XV reitera la doctrina pontificia acerca de la legitimidad de las desigualdades proporcionadas y justas ${ }^{24}$.

d. Causa moral: la concupiscencia y la codicia de los bienes temporales azuzadas por las ideologías de la Modernidad han hecho que la sociedad olvide el destino eterno y sus exigencias, que deben moldear la vida temporal ${ }^{25}$.

Ante este escenario, se subraya que la Iglesia debe continuar en su interior la lucha contra el modernismo, no solo en sus "errores" doctrinarios, sino también en su “espíritu”, y en sus “tendencias”. Para tales efectos se renueva explícitamente, en lo teórico, la postura de San Pío $\mathrm{X}^{26}$.

${ }^{22}$ Ibíd., 7.

${ }^{23}$ Este pasaje, como el anterior, suele ser frecuentemente olvidado por quienes interpretan los proyectos de paz de Benedicto XV en un sentido puramente humanitario. El texto es esencial. Permítasenos citarlo en su original latino: "Meminerint hoc principes rectoresque populorum, ac videant num prudens ac salutare consilium cum potestati publicae tum civitatibus sit a sancta Iesu Christi religione discedere, a qua tantum ipsa potestas habet roboris et firmamenti. Etiam atque etiam considerent, num doctrinam Evangelii et Ecclesiae velle a disciplina civitatis, a publica iuventutis institutione exclusam, civilis sapientiae sit. Nimis experiendo cognitum est, ibi hominum iacere auctoritatem, unde exsulet religio. Quod enim primo nostri generis parenti, cum officium deseruisset, contigit, idem civitatibus usu venire solet. Ut in illo, vix voluntas a Deo defecerat, effrenatae cupidines voluntatis repudiarunt imperium: ita ubi qui res moderantur populorum, divinam contemnunt auctoritatem, ipsorum auctoritati illudere populi consueverunt. Relinquitur sane, quod assolet, ut ad turbidos motus comprimendos vis adbibeatur: sed quo tandem fructu? Vi corpora quidem, non animi comprimuntur". Su versión en español ibíd., 8.

${ }^{24}$ Ibíd., 9. La referencia al magisterio político precedente es explícita y precisa: "No Nos parece necesario repetir ahora los argumentos que prueban hasta la evidencia lo absurdo del socialismo y de otros semejantes errores. Ya lo hizo sapientísimamente León XIII Nuestro Predecesor, en memorables Encíclicas; y vosotros [...] cuidaréis con vuestra diligencia de que tan importantes enseñanzas no caigan en el olvido”. Ibid.

${ }^{25}$ Ibíd., 11. Para disipar este mal, la encíclica propone la "filosofía de las bienaventuranzas", Ibíd., 12. La práctica de esta filosofía de vida es de tanta eficacia que alcanzaría a remediar los problemas políticos y sociales: "a medida que esta fe crezca entre los hombres, decrecerá en ellos el afán inmoderado de alcanzar los fingidos bienes de la tierra, y renaciendo a la caridad, gradualmente cesarán las luchas y contiendas sociales”. Ibíd.

${ }^{26}$ Ibíd., 16. "Non nova, sed noviter, no cosas nuevas sino de un modo nuevo", puntualiza el Pontífice, refiriéndose a la postura práctica respecto de los cambios admisibles. 


\section{La nueva doctrina sobre la paz.}

La actividad incansable de Benedicto XV por lograr la paz entre los pueblos beligerantes, tuvo muchas manifestaciones. De ahí se puede deducir toda una doctrina acerca de la paz europea y mundial.

A mediados del año 1915, en el primer aniversario de la guerra, el Pontífice convoca a los beligerantes a terminar con el conflicto $\operatorname{armado}^{27}$, pero la iniciativa fracasa $^{28}$.

Seis meses después, en Nostris Profecto propone algunas pautas para el arreglo pacífico de la contienda: la eliminación de toda pretensión injusta o excesiva, la necesidad de concesiones por ambas partes, el estudio conjunto de las diferentes pretensiones $^{29}$.

En Dès le début ${ }^{30}$ constata que no han sido atendidas las exhortaciones pontificias a la paz, a una "paz estable y digna para todos". A cambio, el mundo sigue sufriendo la "matanza inútil". Un dramático suicidio para Europa que no quiere detener su andar hacia el abismo.

El documento explicita los tres objetivos del Pontificado durante la guerra: (a) guardar una "perfecta imparcialidad", como conviene al Padre común de los pueblos $^{31}$; (b) hacer todo el bien posible "sin acepción de personas, ni distinción de nacionalidad ni de religión", según lo manda la caridad; (c) cumplir con la misión pacificadora, a objeto de poner fin a la catástrofe y conciliar a los pueblos, rumbo a una "paz justa y duradera" 32 .

${ }^{27}$ Benedicto XV, exhortación apostólica Allorché fummo chiamati, del 28 de julio de 1915 , a los pueblos beligerantes y a sus gobiernos en el primer aniversario de la guerra, en $A A S$., 7 (1915), pp. 365-368.

${ }^{28}$ El Pontífice se queja de la infructuosa recepción de su llamado en BenEDicto XV, Alocución consistorial Nostris Profecto, del 6 de diciembre de 1915, en AAS., 8 (1915), pp. 509-513; y Benedicto XV, Carta al Cardenal Gasparri, secretario de Estado, del 5 de mayo de 1917, en AAS., 9 (1917), pp. 265-267.

${ }^{29}$ No hay que olvidar que el Pontífice aún muestra nostalgia por del ideal de Cristiandad. "Europa -sostiene- ha comenzado a caer de la altura moral a que se levantó cuando vivía según principios del cristianismo"'. Luego de describir en términos entrañables la guerra, advierte -como lo hacían los Papas de la edad cristiana- que los gobernantes son responsables ante "el Eterno y Supremo Juez" de todos sus actos de la vida pública. Benedicto XV, Nostris Profecto, cit. (n. 28), s/n. Utilizamos la versión italiana en línea de la Librería Editrice Vaticana.

${ }^{30}$ Benedicto XV, Exhortación Apostólica Dès le début, del 1 de octubre de 1917, a los jefes de los Estados en guerra para que hallen una vía para la paz; original en Actes de S.S. Benoît XV, I, pp. 181-183. Utilizamos la versión francesa en línea de la Librería Editrice Vaticana.

${ }^{31}$ A inicios del año 1915, Benedicto XV había definido la posición de estricta imparcialidad de la Iglesia: ésta no puede ponerse al lado de ninguna de las partes beligerantes; está por encima de ellas, manteniendo unido a los que la guerra mantiene separados. BENEDICTO XV, Alocución consistorial del 22 de enero de 1915, en $A A S$., 7 (1915), pp. 33-36.

${ }^{32}$ Benedicto XV, Dès le début, cit. (n. 30) s/n. Hay que connotar que la "no distinción de religión", no implica indiferentismo, pues se refiere al ejercicio de la caridad en su dimensión primariamente material (asistencia al hambriento, al herido, al niño huérfano, etc.), para lo cual no tiene sentido, en el contexto de la Gran Guerra, condicionar la ayuda a la filiación religiosa. No hay que olvidar, sin embargo, que es el amor de caridad el que invoca el Pontífice ([...] "sans distinction de nationalité ou de religion, ainsi que Nous le dicte aussi bien la loi universelle de la charité que la suprême charge spirituelle à Nous confiée par le Christ’'). En su sentido propio, el amor de 
Por ello, hace un nuevo llamado, con una propuesta concreta a partir de la cual negociar. La propuesta es inspirada por una idea central: "subordinar el poder material de las armas al poder moral del derecho". Y contiene los siguientes puntos: (i) reducción simultánea y recíproca de los armamentos por parte de todos los pueblos beligerantes; (ii) manteniento del orden público en cada Estado en grado necesario y suficiente; (iii) acuerdo para sustituir las armas por el arbitraje internacional, con sanción disuasiva para el Estado que, estando sometido a él, rechace sus decisiones; (iv) libertad de las vías de comunicaciones, particularmente por mar; (v) completa y recíproca condonación de los daños y gastos de guerra como regla general; (vi) si hay razones particulares para proceder a una indemnización, se debe obrar con justicia y equidad para todas las partes involucradas; (vii) recíproca restitución de los territorios ocupados (se menciona, ejemplarmente, los casos de Bélgica, Francia y las colonias alemanas) ${ }^{33}$; (viii) los casos pendientes de las disputas territoriales, serán examinados con espíritu conciliador por los contendientes, teniendo en cuenta, en la medida de lo justo y lo posible, los propios intereses en coordinación con los intereses comunes del consorcio humano (se nombran los casos de Armenia, Polonia y los Balcanes) ${ }^{34}$.

Una vez firmada la paz, el Pontífice recuerda un doble deber, negativo y positivo: olvido de las ofensas, odios y enemistades recíprocas, y fraterna reconciliación ${ }^{35}$.

Podría pensarse que con estas ideas se siembra la semilla del entendimiento universal entre los pueblos, con independencia de las creencias religiosas o de las doctrinas políticas. Pero lo cierto, es que el Papa della Chiesa lo que hace es sentar las bases prácticas para una pacificación entre los paises beligerantes, restañar las heridas y restablecer, subsecuentemente, el derecho conculcado por las acciones de guerra ${ }^{36}$. Son sabias normas para una primera cobertura, en el orden natural, de una paz estable. Nada de esto implica el abandono de los principios clásicos del derecho público cristiano ${ }^{37}$.

caridad reconoce una diferencia casi infinita respecto del amor puramente filantrópico, pues en el contexto de la teología católica supone la amistad con Dios Uno y Trino, objeto formal de la caridad y motivo basal de los actos exteriores de ayuda asistencial. Véase BENEDicto XV, Paterno Iam Diu, 24 de noviembre de 1919, sobre la ayuda temporal para los niños necesitados de Europa después de la guerra $A A S$., 11 (1919), pp. 437-443, donde distingue entre caridad (caritatem) y filantropía (atque adeo bumanitatem omnium).

${ }^{33}$ Benedicto XV, Alocución consistorial del 22 de enero de 1915, en AAS., 7 (1915), pp. 33-36, donde propone normas para ocupantes y ocupados.

${ }^{34}$ Benedicto XV, Dès le début, cit. (n. 30), s/n. Sobre el último punto, véase, Benedicto XV, Carta al Cardenal Pompilj, 4 de marzo de 1916, en $A A S$., 8 (1916), pp. 58-60.

${ }^{35}$ Benedicto XV, Carta apostólica Diuturni, de 15 de julio de 1919, al Episcopado alemán, en $A A S$., 11 (1919), pp. 305-306; y Benedicto XV, Carta Amor ille singularis al Arzobispo de París, del 7 de octubre de 1919, en $A A S ., 11$ (1919), pp. 412-414.

${ }^{36}$ A propósito de la situación de Polonia, precisa el Pontífice: "cuando los Estados disputan pacífica o belicosamente acerca de los propios derechos, la Sede Apostólica se mantiene neutral; pero cuando un Estado viola los derechos de otro Estado, la Sede Apostólica está obligada a reprobar y condenar esta violación". BENEDICTO XV, Carta al episcopado polaco del 16 de julio de 1921, en $A A S$., 13 (1921), pp. 424-427.

${ }^{37} \mathrm{El}$ oportuno observar, al respecto, que aún en el plano de las soluciones puramente 
Apenas firmado el armisticio del 11 de noviembre de 1918 (en Le Francport), Benedicto XVI publica Quod Iam Diu ${ }^{38}$. Espera que lo que la historia conocerá como las Conferencias de Paz de París (1919) obtengan la paz ${ }^{39}$.

\section{Conferencias y tratados de paz: ¿Edificando sobre la arena?}

Hemos visto que Benedicto XV advierte a las naciones europeas que deben cesar la lucha y restañar las heridas de un conflicto que a todas luces es fratricida. Pero no se detiene en ese punto, pues superando los horizonte culturales racionalistas y cientificistas de la época, afirma que si los pueblos quieren una paz genuina y duradera, deben volver a someterse a la ley divino-natural, reconociendo en la vida pública la centralidad de la persona de $\mathrm{Cristo}^{40}$.

En este sendido, uno de los mayores dramas de la guerra es que se trata de un conflicto "enrojecido con la sangre de los cristianos" 41.

Concluida la lucha de un modo definitivo, el Pontífice publica Pacem Dei mu$n u s^{42}$. Destaca que la ausencia de hostilidades no equivale a obtener la paz. Con

naturales, el texto termina con la remisión pública al principio de fe, como creencia objetiva y comunitaria de los pueblos, y no como opción subjetiva e individual: "accueillez l'invitation paternelle que Nous vous adressons au nom du divin Rédempteur, Prince de la Paix. Réfléchissez à votre très grave responsabilité devant Dieu et devant les hommes [...]. Que le Seigneur vous inspire des décisions conformes à sa très sainte volonté. Fasse le Ciel, qu'en méritant les applaudissements de vos contemporains, vous vous assuriez aussi, auprès des générations futures, le beau nom de pacificateurs". Benedicto XV, Dès le début, cit. (n. 30), s/n.

${ }^{38}$ BeNedicto XV, encíclica Quod Iam Diu, del 1 de diciembre de 1918, en la que se prescriben oraciones públicas por el congreso de la paz, en $A A S$., 10 (1918), pp. 473-474. El documento constata que "aún no ha venido la paz solemne a poner término a la guerra, pero al menos el armisticio que ha interrumpido el derramamiento de sangre y la devastación en la tierra, en el aire y en el mar ha dejado felizmente abierto el camino para llegar a la paz". Ibid., 1. Para la traducción y numeración seguimos la versión castellana en línea de la Librería Editrice Vaticana.

${ }^{39}$ Una vez acabada la guerra, el Pontífice redobla sus exhortaciones para ir en ayuda de los más débiles. Véase Benedicto XV, Encíclica Annus Iam Plenus, 1 de diciembre de 1920, sobre la ayuda que nuevamente se ha de prestar a los niños más necesitados a causa de la guerra, en AAS., 12 (1920), $\mathrm{n}^{\circ}$ 13, pp. 553-556. Benedicto XV también se preocupa con especial atención por la asistencia al pueblo ruso, después de la Revolución bolchevique. BENEDICTO XV, Carta Le Notizie al Cardenal Gasparri, del 5 de agosto de 1921, en $A A S$., 13 (1921), pp. 428-429, sobre la condición de miseria del pueblo ruso. Análogo desvelo muestra por la crisis alimentaria de la Europa de la posguerra. Véase, en particular, Benedicto XV, Carta Par l'intermediaire a Herbert Hoover, 9 de enero de 1920, en $A A S$., 12 (1920), p. 35.

${ }^{40}$ De las Conferencias de paz de París espera no solo acuerdos que lleven a la concordia, sino "aquel inestimable don de Dios de una paz ajustada a los principios de la justicia cristiana”. Benedicto XV, Quod Iam Diu, cit. (n. 38), 3. En análoga línea, Benedicto XV, Discurso Di accogliere al Sacro Colegio cardenalicio del 24 de diciembre de 1914 en vísperas de Navidad; Benedicto XV, Motu proprio Quartus iam annus del 9 de mayo de 1918; y Benedicto XV, Encíclica Quod iam diu del 1 de Diciembre de 1918 promulgada para prescribir oraciones públicas por el congreso por la paz internacional. Los tres documentos pueden revisarse en la edición en línea de la Libreria Editrice Vaticana.

${ }^{41}$ Benedicto XV, Exhortación apostólica Ubi primum, 8 de septiembre de 1914. Utilizamos la edición italiana en línea de la Librería Editrice Vaticana.

${ }^{42}$ Benedicto XV, Encíclica Pacem Dei munus, 23 de mayo de 1920, sobre la restauración cristiana de la paz, en $A A S$., 12 (1920), pp. 209-218. Para la numeración y traducción, la edición castellana en línea de la Libreria Editrice Vaticana. 
una notable agudeza preanuncia tempranamente los gérmenes de la Segunda Guerra Mundial ${ }^{43}$.

Para el pontífice la reconciliación sólo es profunda y durable si se articula en torno a la caridad cristiana. Esta es el fundamento de la paz estable, pues es capaz de extirpar los odios, se extiene a los enemigos, hace posible perdonar por la gracia, e incluso ayudar al enemigo ${ }^{44}$. La ley de la caridad alcanza a toda la comunidad internacional ${ }^{45}$.

Sin embargo, la Sociedad de las Naciones, recientemente creada (1919), se constituye como una institución laica. La Iglesia le prestará su apoyo cuando se trate de conseguir bienes universales, o, en términos de la encíclica, en "todas las empresas que se acometan en pro de la justicia y de la caridad ${ }^{\prime 46}$.

Ante la formación de la Sociedad de las Naciones, que excluye de su membresía a la Santa Sede, el Pontífice advierte, sin embargo, que en la reconstrucción de Europa no se debe abandonar el influjo de la fe y la moral cristianas tanto en la vida pública como en las relaciones internacionales. Como paradigma histórico coloca la formación de la Cristiandad, nacida de pueblos bárbaros que fueron deponiendo las armas en la medida en que la Iglesia influía en su espíritu y afincaba una nueva civilización ${ }^{47}$. Es un antecedente ejemplar, pues los principios católicos deben volver a informar la civilización europea de cara al futuro. Para tales efectos, primero ha de producirse la reconciliación de los pueblos en el orden temporal, y, luego, la vuelta a la Iglesia de Cristo $^{48}$.

43 "Si bien la guerra ha cesado de alguna manera en casi todos los pueblos y se han firmado algunos tratados de paz, subsisten, sin embargo, todavía las semillas del antiguo odio [...] Y no hay paz estable, no hay tratados firmes, por muy laboriosas y prolongadas que hayan sido las negociaciones y por muy solemne que haya sido la promulgación de esa paz y de esos tratados, si al mismo tiempo no cesan el odio y la enemistad mediante una reconciliación". BENEDICTO XV, Pacem Dei munus, cit. (n. 42), 1.

${ }^{44}$ Ibíd., 6-10.

${ }^{45}$ Ibíd., 11.

${ }^{46}$ Ibíd., 14.

${ }^{47}$ Es otro texto que no se suele recordar: "La historia demuestra que los pueblos bárbaros de la antigua Europa, desde que empezaron a recibir el penetrante influjo del espíritu de la Iglesia, fueron apagando poco a poco las múltiples y profundas diferencias y discordias que los dividían, y, constituyendo, finalmente, una única sociedad; dieron origen a la Europa cristiana, la cual, bajo la guía segura de la Iglesia, respetó y conservó las características propias de cada nación y logró establecer, sin embargo, una unidad creadora de una gloriosa prosperidad". Cita a continuación a San Agustín, De civitate Dei XIX 17 y San Agustín, De moribus Ecclesiae catholicae I, 3. Benedicto XV, Pacem Dei munus, cit. (n. 42), 14.

${ }^{48}$ Vale la pena reproducir el texto: "Por lo cual, volviendo al punto de partida de esta nuestra carta, exhortamos en primer lugar, con afecto de Padre, a todos nuestros hijos y les conjuramos, en el nombre de Nuestro Señor Jesucristo, para que se decidan a olvidar voluntariamente toda rivalidad y toda injuria recíproca y a unirse con el estrecho vínculo de la caridad cristiana, para la cual no hay nadie extranjero. En segundo lugar exhortamos encarecidamente a todas las naciones para que, bajo el influjo de la benevolencia cristiana, establezcan entre sí una paz verdadera, constituyendo una alianza que, bajo los auspicios de la justicia, sea duradera. Por último, hacemos un llamamiento a todos los hombres y a todas las naciones para que de alma y corazón se unan a la Iglesia católica, y por medio de ésta a Cristo, Redentor del género humano; de esta manera, con toda verdad podremos dirigirles las palabras de San Pablo a los Efesios, 
En el documento, insiste en que es a la Iglesia a quien Dios otorgó una especial misión para apaciguar a las gentes, por lo que Europa haría bien en no darle la espalda después de tan grande desgracia.

A este propósito, en Principi apostolorum Petro ${ }^{49}$ afirma que el nuevo orden no será orden sino en Cristo, por Cristo y con Roma: "La horrorosa guerra ha terminado y hay un cierto nuevo orden para muchas naciones, especialmente en Oriente. Nos, junto con ustedes y con todos los hombres de buena voluntad, hemos de esforzarnos por restaurar en Cristo lo que queda de la cultura humana y civil, y atraer a la equivocada sociedad de los hombres a Dios y a su Santa Iglesia. Pese a que las instituciones de nuestros antepasados fracasaron, los asuntos públicos están en tumulto, y todo lo humano se halla confundido, sólo la Iglesia Católica no vacila nunca, sino que por el contrario mira confiadamente al futuro. Sólo Ella ha nacido para la inmortalidad, confiando en las palabras dirigidas a San Pedro: "sobre esta piedra edificaré mi Iglesia, y las puertas del infierno no prevalecerán contra ella" 50 .

Lo que pareciera una aspiración homelética es en realidad una imprecación a la pertinacia de los dirigentes de Europa en seguir el surco de emancipación abierto por la Modernidad, que ha conducido a un "nuevo paganismo" respecto, Pacem Dei munus no deja de sorprender por la clarividencia con que escruta las consecuencias: a la sombra de los tratados de paz sobrevive el germen de la discordia que estos no apagarán ${ }^{52}$.

Por eso en $A L e e^{53}$ declara que si bien el término de la guerra es bienvenido, desde el ángulo de la fe, la calamidades actuales no tendrán fin hasta que "los hombres vuelvan a Dios". Es la "sociedad contemporánea", la sociedad temporal la que debe "retornar a la escuela del Evangelio". En el orden de las causas

etc.”. Benedicto XV, Pacem Dei munus, cit. (n. 42), 15. Un poco más atrás, ha recalcado que los pueblos han de unirse "en los principios de la ley cristiana" y en la Iglesia universal ("foederatis autem christiana lege nationibus, quicquid iustitiae et caritatis causa susceperint, non studium operamque suam desiderari sinet Ecclesia, quae cum absolutissimum sit societatis universalis exemplar'). Ibíd., 14.

${ }^{49}$ Benedicto XV, Encíclica Principi apostolorum Petro, del 5 de Octubre de 1920, proclamación de San Efrén el Sirio, como doctor de la Iglesia, en AAS., 12 (1992), pp. 459-471. Para la traducción y numeración utilizamos la versión digital del CENTRo DE Estudios y DocumenTACión PAdRe Hurtado.

${ }^{50}$ Benedicto XV, Encíclica Principi apostolorum Petro, cit. (n. 49), 15.

${ }^{51}$ En Gratum vehementer se advierte sobre el "el cáncer de este paganismo nuevo que corroe la moral privada y pública”, el que no será enmendado por las conferencias políticas internacionales que se limitan a declamar sin regenerar las costumbres. Los acuerdos de paz quedan en los archivos, pero no penetran en la sociedad ni se convierten en leyes efectivas o costumbres mientras no se acuda a los principios fundamentales de la justicia y de la equidad y no se conforme la vida pública a la pureza de la moral cristiana. Ante la pervivencia del espíritu de discordia después de la guerra, el Pontífice subraya la necesidad de una renovación de la sociedad temporal (el "orden civil", las "costumbres" sociales, la "vida individual y familiar") según el espíritu cristiano. BENEDICTO XV, Alocución consistorial Gratum vehementer, 7 de marzo de 1921, en $A A S$., 13 (1921), pp. 121-123.

${ }^{52}$ Benedicto XV, Pacem Dei munus, cit. (n. 42), 1.

${ }^{53}$ Benedicto XV, Alocución A Lei, al Sacro Colegio de Cardenales, en la Vigilia de la Solemnidad de Navidad del 24 de diciembre de 1918. Seguimos la edición en línea en italiano de la Librería Editrice Vaticana. 
primeras, es la "impiedad de la vida pública", de los Estados, el "ateísmo eregido en sistema de pretendida civilización" lo que ha arrastrado a la catástrofe. En tal perspectiva, la paz no es mero fruto del acuerdo entre los pueblos, sino "un don de Dios, para lo cual hay que satisfacer su justicia, con el retorno de los hombres" 54 .

En Sacra Propediem remacha la idea: la verdadera paz, la que busca el género humano, "no es una paz elaborada por lo que aconseja la terrenal prudencia, sino la paz que Cristo trajo al mundo". Solo la sumisión a la Ley de Dios puede ordenar lo que hay de desordenado en el hombre. Ningún intento de acuerdo entre las naciones que esquive este punto puede perdurar. Sería edificar sobre la arena ${ }^{55}$.

\section{LOS PRONUNCIAMIENTOS SOBRE EL NATURALISMO POLÍTICO,}

\section{EL LAICISMO Y LAS LIBERTADES MODERNAS}

Como prolongación de la doctrina precedente sobre la guerra y sus causas más profundas, Benedicto XV aborda de manera muy precisa el problema del naturalismo político, el laicismo y las libertades modernas, sistema opuesto al derecho público cristiano y a los principios políticos de la Cristiandad. Permiten precisar los presupuestos de la paz y de la justicia entre los pueblos que propone el Pontífice. Respecto del laicismo y las libertades modernas, lo relevante de la doctrina del Papa della Chiesa no es tanto su contenido, pues reitera el corpus político de sus predecesores, sino su diagnóstico en relación con la circunstancias que le rodean y la calificación de su especial peso magisterial.

\section{El problema del naturalismo político}

En Humani generis redemptionem, Benedicto XV evalúa la época que ha producido la Gran Guerra como parte de un proceso histórico de apostasía de los gobiernos y naciones. El terrible conflicto con su inútil matanza es la manifestación más atormentada del proceso, marcado por dos factores: la malignidad del laicismo y la caída en las "vergonzosas prácticas del paganismo" "56. Algo análogo dice In Hac Tanta al referir "estos tiempos tenebrosos y estas perturbaciones de la cosa pública" "57. O en Spiritus Paraclitus, donde se describe el siglo como aquel "en que numerosos espíritus se levantan con orgullosa terquedad contra la soberana autoridad de la revelación divina y el Magisterio de la Iglesia"58. Por ello, en Sacra

\footnotetext{
${ }^{54}$ Ibíd., s/n.

${ }^{55}$ Benedicto XV, Encíclica Sacra Propediem, 6 de enero de 1921, con ocasión del séptimo centenario de la fundación de la Tercera Orden Franciscana; en $A A S$., 13 (1921), pp. 33-41.

56 "En el estado de la moral pública y privada, así como en las instituciones y leyes de las naciones, hay una total indiferencia y desprecio de lo sobrenatural, así como una caída gradual lejos de la severa virtud cristiana, y los hombres están retrocediendo hacia las vergonzosas prácticas del paganismo". Benedicto XV, Encíclica Humani generis redemptionem, 15 de junio de 1917, sobre la predicación de la divina palabra; en $A A S ., 9$ (1917), pp. 305-317.

${ }^{57}$ Benedicto XV, Encíclica In Hac Tanta, 14 de mayo de 1919, con ocasión del décimo segundo siglo del inicio de la misión apostólica de San Bonifacio, en AAS., 10 (1918), pp. 209-221.

${ }^{58}$ Benedicto XV, Encíclica Spiritus Paraclitus, 20 de septiembre de 1920, sobre las Sagradas Escrituras, con motivo del $15^{\circ}$ centenario de la muerte de San Jerónimo, en $A A S ., 12$ (1920), pp. 385-422.
} 
Propediem se exhorta a reajustar la vida temporal a la ley cristiana. El mal presente "que corroe las entrañas de la sociedad" es el "inveterado olvido y desprecio de los principios cristianos", del que deriva la actual "lucha de clases"

Bonum sane et salutare ${ }^{60}$ precisa que más allá de las causas de la guerra señaladas en Pacem Dei munus (y Ad beatissimi), hay otra de carácter más específica, pues se vincula con la defección propia de la edad moderna. Se trata del naturalismo que Benedicto XV describe por sus frutos ${ }^{61}$.

Con el vocablo naturalismo se engloba todo el conjunto de sistemas filosóficos, corrientes políticas, sistemas jurídicos y postulados morales que niegan el orden sobrenatural y que, en consecuencia, hacen del hombre un ente autónomo.

El Pontífice precisa que el "naturalismo" es la "peste del siglo", que "anida en las íntimas víceras de la sociedad” contemporánea, y que es mucho más grave que la enemistad entre los pueblos como causa profunda de la Gran Guerra y de la futura perturbación. A continuación describe de manera notable como el naturalismo ha alejado a los pueblos y a las instituciones temporales de la fe y de la moral viva del cristianismo ${ }^{62}$.

Una de las consecuencias más nefastas de este naturalismo ha sido la proyección ideológica de esa autonomía a todos los campos donde ejerce su acción la autoridad divina y humana. Tras ella, late el sueño de la construcción de la "República universal", laica e igualitaria, de corte comunista ${ }^{48}$.

La solución social se coloca en la regeneración de la familia cristiana, como

\footnotetext{
${ }^{59}$ Benedicto XV, Encíclica Sacra Propediem, 6 de enero de 1921, con ocasión del séptimo centenario de la fundación de la Tercera Orden Franciscana; en $A A S$., 13 (1921), pp. 33-41.

${ }^{60}$ Benedicto XV, Motu proprio Bonum sane et salutare, del 25 de julio de 1920, sobre las solemnidades del $50^{\circ}$ Aniversario de la declaración de San José como Patrono de la Iglesia Católica, en $A A S$., 12 (1920), pp. 313-317. Para la traducción y numeración nos servimos de la edición digital del Centro de Estudios y Documentación Padre Hurtado.

61 “En Nuestra Encíclica [Pacem Dei] [...] señalábamos cuánto [...] falta para lograr restablecer la tranquilidad general del orden después de esa grave contienda de la guerra pasada. Pero ahora debemos atender a otra causa de perturbación mucho más grave por cuanto se infiltró en las mismas venas y entrañas sociedad humana; pues, se comprende que en ese tiempo en que la calamidad de la guerra absorbía la atención de los hombres, el naturalismo, esa peste perniciosísima del siglo, los corrompiera totalmente y que, donde se desarrollaba bien, debilitaba el deseo de los bienes celestiales, ahogaba las llamas de la caridad divina, sustraía al hombre de la gracia de Cristo que sana y eleva y, despojándolo finalmente de la luz de la fe y abandonándolo a las solas fuerzas enfermas y corrompidas de la naturaleza, permitía las desenfrenadas concupiscencias del corazón”. Benedicto XV, Bonum sane et salutare, cit. (n. 60), 2. En el no 3 se apunta también a la relajación moral que la guerra trajo a la institución del matrimonio y la familia.

${ }^{62}$ Textualmente: "Nunc autem altera est perturbationis causa attendenda eaque longe maior, utpote quae in venis atque visceribus humanae societatis insideat. Scilicet eo tempore calamitas belli gentes occupavit, cum penitus eas naturalismus infecerat maxima illa saeculi lues, quae, ubi invaluit, caelestium bonorum desiderium debilitat, flammam divinae caritatis opprimit, hominem sananti et elevanti Christi gratiae subtrabit, eumque, fidei lumine denique orbatum et solis naturae infirmis corruptisque viribus instructum, effrenatis animi cupiditatibus permittit. Conversa igitur unice studia ad res caducas nimis multi mortales cum haberent, cumque proletarios inter et locupletes infensissimae aemulationes et simultates intercederent, mutuasclassium inimicitiam adauxit acrioresque reddidit belli diuturnitas et magnitudo, ideo praesertim quod binc intolerandam multitudini annonae caritatem, illinc subitam fortunarum affluentiam perpaucis attulit'. BENEDICTO XV, Bonum sane et salutare, cit. (n. 60), 4.
} 
punto de partida de la restauración de una civilización guiada por la $\mathrm{fe}^{63}$. Este aspecto, que ya se encontraba presente en León XIII y San Pío X, será tratado con gran detención por Pío XI, Pío XII y también por Juan Pablo II, aunque con ciertas variantes criteriológicas.

En un horizonte teológico, Spiritus paraclitus ${ }^{64}$ propone otro recurso para enfrentar el naturalismo: la ciencia de las Sagradas Escrituras, que si está exenta de todo modernismo, es especialmente apta para enfrentar a quienes rechazan la verdad divina, a quienes "se levantan con orgullosa terquedad contra la soberana autoridad de la revelación divina y del magisterio de la Iglesia" ${ }^{65}$.

Para el documento, uno de los frutos típicos del recto estudio de las Escrituras es la sumisión de los hombres a la voluntad de Dios, de la que se puede esperar la vuelta de las sociedades al seno de la Iglesia ${ }^{66 .}$

Finalmente, en In Praeclara Summorum afirma que "la savia de la filosofía y teología cristianas" han permitido conocer el "conjunto de leyes divinas para el gobierno y administración de los asuntos públicos [...] Para extender la grandeza de la patria, no puede descuidarse la justicia y el derecho de Dios, en cuya con-

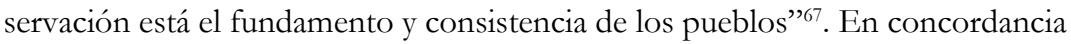
con esta idea, en Fausto Appetente se destaca la justa autoridad de la Iglesia en las cosas temporales, por ejemplo ante los movimientos populares o la injusticia de los príncipes $^{68}$.

\section{Una sintesis de los errores políticos modernos anudados por el laicismo}

La carta Anno iam exeunte ${ }^{69}$ tipifica en un solo todo el nudo laicista que une el liberalismo, el socialismo y las libertades modernas: “Así como se hace profesión de rechazar públicamente la autoridad de la Iglesia y ya no se tiene a la religión como guardiana y salvaguarda del derecho, del deber y del orden en la Ciudad, se ha entregado al pueblo y no a Dios el origen del poder; se pretende que entre los hombres la igualdad de naturaleza entraña la igualdad de derechos; que los argumentos de hacer lo que se quiera definen lo que está permitido, con excepción de lo que prohíbe la ley; que nada tiene fuerza de ley si no es emanado de la multitud; y lo que sobrepasa a todo, se entiende que la máxima libertad es la

${ }^{63}$ Ibíd., 8.

${ }^{64}$ Benedicto XV, Encíclica Spiritus paraclitus, del del 20 de septiembre de 1920, sobre las Sagradas Escrituras, con motivo del $15^{\circ}$ centenario de la muerte de San Jerónimo, en $A A S$, 12 (1920), pp. 385-422. Para la traducción y numeración nos servimos de la edición en línea de la Librería Editrice Vaticana.

${ }^{65}$ Ibíd., 42.

${ }^{66}$ Ibíd., 65.

${ }^{67}$ Benedicto XV, Encíclica In Praeclara Summorum, 30 de abril de 1921, en el sexto centenario de la muerte de Dante Alighieri, en $A A S ., 12$ (1921), pp. 209-217.

${ }^{68}$ Benedicto XV, Encíclica Fausto Appetente Die, 29 de junio de 1921, sobre el séptimo centenario del nacimiento de Santo Domingo, en $A A S$., 13 (1921), pp. 329-335.

${ }^{69}$ Benedicto XV, Carta Anno iam exeunte, del 7 de marzo de 1917, al P. Joseph Hiss, superior general de los marianistas, con ocasión del centenario de la consagración de dicha sociedad; original latín en $A A S$., 9 (1917), pp. 171-175. 
de pensar lo que se quiera en materia de religión, incluso públicamente, bajo el pretexto de no perjudicar a la persona" ${ }^{\text {"70 }}$.

Es interesante constatar, cómo en la mente de Benedicto XV se identifican las distintas vertientes anticristianas de la Modernidad política:

- El laicismo del Estado y de la vida pública. Para ahorrar explicaciones, al laicismo se le identifica directamente con la exclusión de la verdad divina de la comunidad política ("se hace profesión de rechazar públicamente la autoridad de la Iglesia y ya no se tiene a la religión como guardiana y salvaguarda del derecho, del deber y del orden en la Ciudad").

- La soberanía popular, dogma común al liberalismo y al socialismo, y punto de partida de la inmanentización del poder político, también se encuentra referida ("se ha entregado al pueblo y no a Dios el origen del poder") ${ }^{71}$.

- El socialcomunismo tiene su reseña oportuna ("se pretende que entre los hombres la igualdad de naturaleza entraña la igualdad de derechos").

- Las libertades modernas son descritas desde su base genética: la libertad de conciencia, de pensamiento y de creencia ("que los argumentos de hacer lo que se quiera definen lo que está permitido, con excepción de lo que prohíbe la ley"). $\mathrm{Su}$ "test de reconocimiento" se encuentra en la libertad moderna de religión ("y lo que sobrepasa a todo, se entiende que la máxima libertad es la de pensar lo que se quiera en materia de religión, incluso públicamente, bajo el pretexto de no perjudicar a la persona").

- Finalmente, encontramos el democratismo positivista ("que nada tiene fuerza de ley si no es emanado de la multitud") ${ }^{72}$.

Como solución al problema del laicismo y del "derecho nuevo", Benedicto XV impulsa la observancia de la doctrina social católica a través de asociaciones católicas de diversa naturaleza, con especial preocupación por la descristianización de la vida pública y la lucha de clases socialista ${ }^{73}$.

\footnotetext{
${ }^{70}$ Dice el texto latino: "Nam, Ecclesiae auctoritate publice reiecta, cum desitum esset iuris, officii atque ordinis in civitate custodem ac vindicem haberi Religionem, iam placuit a populo, non a Deo, potestatem oriri; bomines inter se, ut natura, ita iure pares omnes esse; quod cuique libuisset, id licere, nisi quae lex probiberet; nibil habere vim legis, quod non multitudo iussisset; libertates maxime sentiendi de religione, vel vulgandi quidquid quisque voluisset, nullis contineri finibus, dum noceret nemini”. BENEDICTO XV, Anno iam exeunte, cit. (n. 69), p. 172. La traducción es nuestra.

${ }^{71}$ A este propósito, Benedicto XV reitera la doctrina de León XIII sobre la sumisión y obediencia al poder constituido: "christiani hominis (est) ei se fideliter subicere potestati quae reipsa dominetur". Benedicto XV, Carta al episcopado portugués, del 18 de diciembre de 1919, en $A A S ., 12$ (1920), pp. 32-33. Sobre la debida observancia a la ley positiva, para mantener el orden público y privado, Benedicto XV, Alocución al consistorio del 4 de diciembre de 1916, en $A A S ., 8$ (1916), p. 467.

${ }^{72}$ A propósito del democratismo positivista, dice en otro lugar: "los males presentes se deben a la situación política y económica, pero la raíz profunda es otra: el olvido de la ley eterna; el cumplimiento del deber no puede apoyarse sólidamente en la mera ley; sino en la obediencia debida a Dios". Benedicto XV, Carta al Episcopado de Umbría, 14 de junio de 1920, en $A A S ., 12$ (1920), p. 292.

${ }^{73}$ En Benedicto XV, Carta Solti nos, del 11 de marzo de 1920, al obispo de Bérgamo, sobre la observancia de la doctrina social católica, en AAS., (1920) 12 (1920), pp. 109-112, se advierte contra las revueltas impulsadas por la Revolución socialista, síntoma y causa de la
} 


\section{La condena de los principios de la Revolución Francesa. Las libertades modernas en} boca de los falsos profetas

En la Alocución con motivo de la promulgación de la heroicidad de las virtudes de Marcelino Champagnat ${ }^{74}$, Benedicto XV se pronuncia formalmente contra los principios de la Revolución Francesa.

El Pontífice sostiene que Revolución Francesa contienen la "suma de las enseñanzas de los falsos profetas". La idea es de tal importancia que merece se citada in extenso: "La libertad preconizada por aquellos profetas no abría las puertas para el bien, sino para el mal; la fraternidad que predicaban no saludaba a Dios como Padre único de todos los hermanos; y la Igualdad que anunciaban no se basaba en la identidad de origen, ni en la común Redención, ni en el mismo destino de todos los hombres. Eran profetas que predicaban una igualdad destructiva de la diferencia de clases querida por Dios en la sociedad; eran profetas que llamaban hermanos a los hombres para quitarles la idea de sujeción de unos con relación a los otros; eran profetas que proclamaban la libertad de hacer el mal, de llamar luz a las tinieblas, de confundir lo falso con lo verdadero, de preferir aquel a este, de sacrificar al error y al vicio los derechos y las razones de la justicia y de la verdad".

"Una simple mirada sobre las llagas que los principios del 89 abrieron en el seno de la sociedad civil y religiosa, patentizan cómo aquellos principios contenían la suma de la enseñanza de los falsos profetas: a fructibus eorum cognoscetis eos"75.

descristianización de la sociedad. El espíritu cristiano debe volver a inspirar la sociedad terrena. En Benedicto XV, Carta al Cardenal Gusmini, del 22 de junio de 1920, en AAS., 12 (1920), pp. 292-293; y Benedicto XV, Carta Intelleximus al Patriarca de Venecia, del 14 de junio de 1920, sobre los principios cristianos de orden social, en $A A S$., 12 (1920), pp. 290-291, hay nuevas advertencias contra el socialismo, y se insta a que la sociedad temporal se apoye en los "principios católicos". En esa misma línea, sobre las asociaciones católicas y la necesidad de la acción social por ellas desarrolladas, Secretaría de Estado, Carta a José de la Torre, Presidente de la Unión Popular, 25 de febrero de 1915, en $A A S$., 7 (1915), p. 138; Secretaría de Estado, Carta al Conde Medolago Albani, Presidente de la Unión Económico Social, 13 de agosto de 1915, en $A A S$., 7 (1915), p. 453; Benedicto XV, Carta al Arzobispo de Milán, 22 de mayo de 1916, en $A A S$., 8 (1916), p. 261; Benedicto XV, Carta al Presidente General de la Sociedad de San Vicente de Paul, 3 de febrero de 1917, en $A A S$., 9 (1917), p. 168; Benedicto XV, Carta apostólica Romanorum Pontificum, del 8 de abril de 1921, en $A A S$., 13 (1921), p. 372, sobre la Sociedad Jesucristo Obrero.

${ }^{74}$ Benedicto XV, Discurso del 11 de julio de 1920, con motivo de la promulgación de la heroicidad de las virtudes de Marcelino Champagnat, en L'Osservatore Romano, edición del 12-13 de julio de 1920 .

${ }^{75}$ Otros trechos del discurso complementan estas ideas: "Basta considerar los principios del siglo XIX para reconocer que muchos falsos profetas aparecieron en Francia, y a partir de ahí se proponían difundir por todas partes la maléfica influencia de sus perversas doctrinas. Eran profetas que tomaban aires de vengadores de los derechos del pueblo, preconizando una era de Libertad, Igualdad y de Fraternidad. Quien no veía que estaban disfrazados de ovejas "in vestimentis ovus" [...] No es de maravillar que contra tales falsos profetas debiera resonar una palabra terrible: 'guaellos', 'attendite la falsis prophetis'. Marcelino Champagnat oyó esa palabra; entendió también que no había sido dicha sólo para él, y pensó en hacerse el eco de ella junto a los hijos del pueblo, que veía como los más expuestos a ser víctimas de los principios de 1789 , debido a la propia inexperiencia y a la ignorancia de sus padres en materia de religión. 'Attendite la falsis prophetis': he ahí las palabras que repetía aquel que anhelaba detener el torrente de errores 
Como sus predecesores, el Pontífice remarca que las libertades modernas constituyen una licencia para el mal y el error, puesto que al suponer que no existe una verdad trascendente, ni una ley moral eterna (o que éstas no pueden ser conocidas con certeza), tanto da seguirlas como no seguirlas. En consecuencia, no son susceptibles de ser abrazadas comunitariamente por la sociedad civil, como en la época de la Cristiandad. Tampoco tiene sentido un reconocimiento de ellas por parte del poder público, o el orden jurídico. Estos se vuelven laicos por definición.

Asimismo, las libertades modernas -que no son cualesquieras libertades, sino libertades revolucionarias- desatan los vínculos constitutivos que sustentan las autoridades naturales. Son un medio notable para establecer y expandir el poder soberano -absoluto- del Estado moderno, consecuencia que la Alocución no saca pero que es fácil inferir.

4. La enseñanza pontificia sobre las relaciones entre la Iglesia y la comunidad politica es un capitulo fundamental de la doctrina católica

En la Alocución consistorial de 13 de junio de $1921^{76}$, Benedicto XV define el tema de las relaciones entre la Iglesia y la sociedad política, tal como lo han enseñado sus predecesores, como capítulo fundamental de la doctrina católica: "illud catholicae doctrinae [...] caput de utriusque potestatis consensione ad bonum civitatis et Ecclesiae bunum".

Tal doctrina no impide mirar a las nuevas circunstancias, pero éstas no anulan los principios, a saber, que, en circunstancias normales, al régimen de unión o concordia entre la Iglesia y el Estado es el ideal, y que la sociedad política -y los titulares del Poder- tiene el deber grave de "religione publica satisfacere".

Complementariamente, la alocución In hac quidem ${ }^{77}$ sostiene que no obstante el amplio interés de los nuevos Estados surgidos tras la Primera Guerra Mundial para establecer relaciones diplomáticas con la Santa Sede, y el interés de ésta en llegar a acuerdos ${ }^{78}$, el canon de referencia para la Iglesia es el cumplimiento de su

y vicios que, por obra y gracia de la Revolución Francesa, amenazaba inundar la Tierra. 'Attendite la falsis prophetis': he ahí las palabras que explican la misión que Marcelino Champagnat abrazó; palabras que no deben ser sepultadas en el olvido por quien quiera estudiar su vida. No deja de tener interés la comprobación del hecho de que Marcelino Champagnat, nacido en 1789, fue destinado a combatir, en su aplicación práctica, precisamente los principios que tomaron el nombre del año de su nacimiento, y después obtuvieron triste y dolorosa celebridad”. BENEDICTO XV, Discurso del 11 de julio de 1920, cit. (n. 74).

${ }^{76}$ Benedicto XV, Alocución consistorial del 13 de junio de 1921, en $A$ AS., 13 (1921), pp. 281-284.

${ }^{77}$ Benedicto XV, Alocución consistorial In hac quidem, del 21 de noviembre de 1921, sobre las relaciones entre la Iglesia y los Estados actuales; en $A A S$., 13 (1921), pp. 521-524. Para la traducción y numeración utilizamos la edición de la Doctrina Pontificia, II: Documentos políticos (Madrid, BAC, 1958), pp. 485-488.

78 “Al renovar la alegría de este amplio consistorio, muchas son nuestras preocupaciones. Pero la mayor de todas es la ordenación de la compleja cuestión de las relaciones mutuas entre la Iglesia y la sociedad política (civilem societatem). Es cosa de todos conocida que, después del reciente conflicto mundial, han surgido nuevos Estados (Respublicas) o han aumentado los Estados antiguos con la anexiones territoriales llevadas a cabo [...]”. BENEDiCTo XV, Alocución 
misión en la sociedad temporal ${ }^{79}$. Esto lleva, más ampliamente, a la doctrina del Reinado Social de Cristo, desarrollada en todos sus alcances políticos, jurídicos y sociales por Pío XI. La doctrina de Benedicto XV se encuentra muy lejos de aprobar lo que hoy se denomina laicidad, ni menos el ideal de una paz internacional puramente humanitaria y panreligiosa ${ }^{80}$.

\section{ConCLUSIÓN}

1. El Pontificado de Benedicto XV (1914-1922) fue marcado por la Primera Guerra Mundial. Tras ella, emerge el principio liberal y laico como marco de organización política nacional e internacional, y, en paralelo, el social-comunismo, como una posibilidad real de dominio de las naciones. El Papa tendrá que enfrentarse a todos estos problemas. Al hacerlo, explicitará elementos doctrinarios relevantes, sea en relación con la paz entre los pueblos, las bases del derecho de gentes, el fin último de las comunidades políticas, la relación entre el Estado y

consistorial In hac quidem, cit. (n. 77), 1. "Pero si los gobernantes de los Estados (Rebuspublicis vel Civitatibus) referidos desean establecer con la Iglesia un acuerdo pacífico más adecuado a las nuevas condiciones creadas por el cambio de los tiempos (aliis condicionibus quae mutatis temporibus) sepan que la Santa Sede -si no existe algún impedimento por otro motivo- no rehusará establecer negociaciones sobre este asunto". BENEDICTO XV, Alocución consistorial In hac quidem, cit. (n. 77), 2. Este principio tuvo diversas aplicaciones prácticas. Particularmente en el caso húngaro y el caso polaco. Para el primero, véase Benedicto XV, carta al Cardenal Csernock, del 12 de marzo de 1919, en AAS., 11 (1919), pp. 122-123; y BENEDicTo XV, carta al Cardenal Csernock, del 11 de septiembre de 1919, en $A$ AS., 11 (1919), pp. 378-379. Para el segundo, BenEDicto XV, Carta al Cardenal Kakorski, del 16 de julio de 1921, en $A A S ., 13$ (1921), pp. 424-427.

79 "Sin embargo, os confirmamos de nuevo, que en estos acuerdos Nos no permitiremos nada contrario a la dignidad o a la libertad de la Iglesia, cuya integridad e incolumidad son sumamente importantes, principalmente en estos tiempos, para la misma prosperidad de la sociedad civil" [...] "Nadie puede negar que la colaboración de la Iglesia y la sociedad política (rei civilis religiosaeque consensionem) es extraordinariamente útil para la tranquilidad del orden público, que es el fundamento de todos los bienes [...] A la paz consignada en los documentos solemnes no ha acompañado de modo alguno la paz de los espíritus, y [...] casi todas las naciones, principalmente las de Europa, se hallan aún hoy agitadas por grandes divisiones tan acerbas, que para su remedio es necesaria cada día más la mano de Dios misericordioso, en la cual está la virtud y el poder [...] la grandeza y el imperio de todas las cosas (I Par. 29, 12)". Benedicto $\mathrm{XV}$, Alocución consistorial In hac quidem, cit. (n. 77). No obstante el contexto diplomático de la Alocución, es evidente que la colaboración o consenso entre Iglesia y Estado que aquí se plantea no dice relación sólo a un proceso concordatario de mutuo entendimiento en aspectos relativos a la libertad de la Iglesia. Importa no sólo el medio, sino el fin. Tales acuerdos deben estar orientados, en última instancia, por la misión de la Iglesia en la sociedad temporal. Por lo demás, ya sabemos que la Santa Sede no tiene problemas en entablar relaciones normales con todos los Estados, si éstos respetan los derechos de la Iglesia. Benedicto XV, Alocución consistorial de 13 de junio de 1921. AAS., 13 (1921), pp. 281-284.

${ }^{80}$ Recuérdese su encíclica Maximum illud, donde opone los "predicadores del error" a los "misioneros de la verdad" católica. El Pontíce prescribe la necesidad de "difundir el catolicismo por toda la tierra". Benedicto XV, Carta apostólica Maximum illud, 30 de noviembre de 1919, sobre la propagación de la fe católica; en $A A S$., 9 (1919), pp. 440-455. Versión española en línea de la Librería Editrice Vaticana, nº 98 y 108. 
la Iglesia o los supuestos morales de la vida pública, que vienen a completar el corpus político-social de León XIII y San Pío X.

2. Sobre este Pontificado pesa una doble injusticia histórica: a partir de la Segunda Guerra Mundial fue relegado al olvido, y su doctrina político-social, que ha vuelto a ser apreciada, es subordinada casi completamente a sus aspectos histórico contingentes, o, con un cierto anacronismo, se le considera un antecedente de lo que viene a madurar después. Pontificado y doctrina, sin embargo, merecen ser analizados de una manera singular y autónoma.

3. Benedicto XV enfrenta la Guerra con una serie de pronunciamientos que pretenden no solo dar término al conflicto desde una postura de imparcialidad, sino conformar un consorcio de naciones que, en lo necesario, cumplan con las exigencias de la justicia natural, y, en lo posible, se rearticulen en torno a la supranacionalidad del Papado, cuya misión es velar por el retorno de los gobiernos y las sociedades temporales a la Ley de Cristo. En este sentido, la Gran Guerra es efecto de una causa profunda: el abandono del principio cristiano por parte de las naciones, lo que produce otras tantas causas inmediatas: ausencia de caridad; desacralización del poder político, erosión del principio de autoridad, voluntarismo nacionalista y democratismo positivista como constitutivos político-jurídicos; igualitarismo socialista, con la consiguiente ruptura de vínculos sociales y lucha de clases; pérdida del horizonte de la vida eterna, como molde de la vida temporal, con el subsecuente materialismo y codicia de los bienes temporales.

4. Durante la Guerra, podría pensarse que el Pontífice formula una nueva doctrina sobre la paz, fundada en el entendimiento universal entre las naciones, con independencia de las creencias religiosas y de las doctrinas políticas. En realidad, lo que hace es sentar las bases prácticas para una pacificación entre los paises beligerantes, el restañamiento de las heridas de un conflicto a todas luces fracticida, y el subsecuente restablecimiento del derecho conculcado por las acciones de guerra. Se trata de sabias normas para una primera cobertura, en el orden natural, de una paz estable. Nada de esto implica el abandono de los principios clásicos del Derecho Público cristiano.

5. Después de la Guerra, Benedicto XV acoge toda acción pacificadora (y asistencial) de las conferencias internacionales y la Sociedad de las Naciones, recién formada, pero supera los horizonte culturales racionalistas y cientificistas de la época, afirmando que si los pueblos europeos quieren una paz genuina y duradera, deben volver a someterse a la ley divino-natural, reconociendo en la vida pública su centralidad, y, más aún, el culto a la persona de Cristo, el dador de aquella paz que no se encuentra en los acuerdos democráticos humanos.

6. La época que ha producido la Gran Guerra es interpretada como parte de un proceso histórico de apostasía de los gobiernos y naciones. El terrible conflicto con su inútil matanza es la manifestación visible y atormentada del proceso, marcado por tres factores: el naturalismo político, el laicismo por parte de los Estados y la caída en el neopaganismo, por parte de las multitudes. Son éstos factores de futura perturbación. Tras ellos, el Pontífice advierte la posibilidad de una nueva guerra, como también la alternativa de una República universal de corte comunista.

7. Como prolongación de la doctrina precedente sobre la guerra, sus causas más profundas, y los factores que señalan el siglo, Benedicto XV aborda de manera 
muy precisa el problema del laicismo y de las libertades modernas, sistema opuesto al derecho público cristiano y a los principios temporales de la Cristiandad. Lo relevante no es tanto su contenido, pues reitera los principios de sus predecesores, sino el diagnóstico de cómo opera en la época y, suplementariamente, la calificación de su especial peso magisterial, pues sostiene que la enseñanza sobre las relaciones entre la Iglesia y la comunidad política es capítulo esencial de la doctrina católica. Particularmente el régimen de unión entre Iglesia y Estado, y el deber grave de "religione publica satisfacere" por parte de las sociedades políticas y los titulares del Poder. Ello abre las puertas a la doctrina del Reinado Social de Cristo, desarrollada en todos sus alcances políticos, jurídicos y sociales por Pío XI.

BibLIOGRAFÍA

\section{Documentos Pontificios}

Benedicto XV, Exhortación apostólica Ubiprimum, 8 de septiembre de 1914. Edición en italiano, Librería Editrice Vaticana: (vatican.va/content/benedict-xv/it.html).

-Encíclica Ad beatissimi del 1 de noviembre de 1914, sobre la guerra mundial y sus causas, en $A A S$., 6 (1914), pp. 615-629. Edición en español del CENTRO DE Estudios y Documentación «Padre Hurtado», El Magisterio Pontificio. De León XIII a Benedicto XVI (Santiago, Pontificia Universidad Católica de Chile, Santiago, 2007, edición digital).

—Discurso Di accogliere al Sacro Colegio cardenalicio del 24 de diciembre de 1914 en vísperas de Navidad. Edición en italiano, Librería Editrice Vaticana: (vatican.va/ content/benedict-xv/it.html).

-Alocución consistorial del 22 de enero de 1915, propone normas para ocupantes y ocupados, en $A A S$., 7 (1915) pp. 33-36.

—Exhortación apostólica Allorché fummo chiamati, del 28 de julio de 1915, a los pueblos beligerantes y a sus gobiernos en el primer aniversario de la guerra; en $A A S$., 7 (1915) pp. 365-368.

-Alocución consistorial Nostris Profecto, del 6 de diciembre de 1915, en AAS., 8 (1915) pp. 509-513. Edición en italiano, Librería Editrice Vaticana: (vatican.va/ content/benedict-xv/it.html)

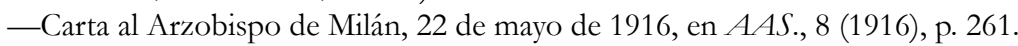

—Carta al Cardenal Pompilj, 4 de marzo de 1916, en $A A S ., 8$ (1916) pp. 58-60.

—Alocución al consistorio del 4 de diciembre de 1916, en $A A S ., 8$ (1916), p. 467.

- Carta al Presidente General de la Sociedad de San Vicente de Paul, 3 de febrero de 1917, en $A A S$., 9 (1917), p. 168.

—Carta Anno iam exeunte, del 7 de marzo de 1917, al P. Joseph Hiss, superior general de los marianistas, con ocasión del centenario de la consagración de dicha sociedad; en $A A S ., 9$ (1917), pp. 171-175.

—Carta al Cardenal Gasparri, secretario de Estado, del 5 de mayo de 1917, en $A A S$, 9 (1917), pp. 265-267.

—Encíclica Humani generis redemptionem, 15 de junio de 1917, sobre la predicación de la divina palabra, en $A A S$., 9 (1917), pp. 305-317. Edición en latín, Librería Editrice Vaticana: (vatican.va/content/benedict-xv/la.html).

—Exhortación Apostólica Dès le début, del 1 de octubre de 1917, a los jefes de los Estados en guerra para que hallen una vía para la paz; en Actes de S.S. Benoît XV, I, 
pp. 181-183. Edición en francés, Librería Editrice Vaticana: (vatican.va/content/ benedict-xv/fr.html)

—Motu proprio Quartus iam annus del 9 de mayo de 1918. Edición en italiano, Librería Editrice Vaticana: (vatican.va/content/benedict-xv/it.html).

—Encíclica Quod Iam Diu, del 1 de diciembre de 1918, en la que se prescriben oraciones públicas por el congreso de la paz; en $A A S$., 10 (1918), pp. 473-474. Edición en español, Librería Editrice Vaticana: (vatican.va/content/benedict-xv/es.html).

-Alocución A Lei, al Sacro Colegio de Cardenales, en la Vigilia de la Solemnidad de Navidad del 24 de diciembre de 1918. Edición en italiano, Librería Editrice Vaticana: (vatican.va/content/benedict-xv/it.html)

—Carta al Cardenal Csernock, del 12 de marzo de 1919, en $A A S$., 11 (1919), pp. 122-123.

—Encíclica In Hac Tanta, 14 de mayo de 1919, con ocasión del décimo segundo siglo del inicio de la misión apostólica de San Bonifacio, en $A A S$., 10 (1918), pp. 209-221. Edición en latín, Librería Editrice Vaticana: (vatican.va/content/ benedict-xv/la.html).

—Carta apostólica Diuturni, de 15 de julio de 1919, al Episcopado alemán, en $A A S$, 11 (1919), pp. 305-306.

—Carta al Cardenal Csernock, del 11 de septiembre de 1919, en $A A S ., 11$ (1919), pp. 378-379.

- Carta Amor ille singularis al Arzobispo de París, del 7 de octubre de 1919, en $A A S$, 11 (1919), pp. 412-414.

—Encíclica Paterno Iam Diu, 24 de noviembre de 1919, sobre la ayuda temporal para los niños necesitados de Europa después de la guerra, en $A A S$., 11 (1919), pp. 437-443.

—Carta al episcopado portugués, del 18 de diciembre de 1919, en $A A S$., 12 (1920), pp. 32-33.

- Carta Solti nos, del 11 de marzo de 1920, al obispo de Bérgamo, sobre la observancia de la doctrina social católica, en $A$ AS., 12 (1920), pp. 109-112.

—Encíclica Pacem Dei munus, 23 de mayo de 1920, sobre la restauración cristiana de la paz; en $A A S$., 12 (1920), pp. 209-218. Edición en español, Librería Editrice Vaticana:

(vatican.va/content/benedict-xv/es.html).

- Carta Intelleximus al Patriarca de Venecia, del 14 de junio de 1920, sobre los principios cristianos de orden social, en $A A S ., 12$ (1920), pp. 290-291.

- Carta al Cardenal Gusmini, del 22 de junio de 1920, en $A A S$., 12 (1920), pp. 292-293.

—Discurso del 11 de julio de 1920, con motivo de la promulgación de la heroicidad de las virtudes de Marcelino Champagnat, en L'Osservatore Romano, edición del 12-13 de julio de 1920 .

- Carta al Episcopado de Umbría, 14 de junio de 1920, en $A A S$., 12 (1920), p. 292.

-Motu proprio Bonum sane et salutare, del 25 de julio de 1920, sobre las solemnidades del $50^{\circ}$ Aniversario de la declaración de San José como Patrono de la Iglesia Católica, en $A A S$., 12 (1920), pp. 313-317. Utilizamos la versión española del Centro de Estudios y Documentación Padre Hurtado, El Magisterio Pontificio. De León XIII a Benedicto XVI (Santiago, Pontificia Universidad Católica de Chile, Santiago, 2007, edición digital).

—Encíclica Spiritus paraclitus, del del 20 de septiembre de 1920, sobre las Sagradas Escrituras, con motivo del $15^{\circ}$ centenario de la muerte de San Jerónimo, en $A A S$, 
12 (1920), pp. 385-422. Edición en español, Librería Editrice Vaticana: (vatican. $\mathrm{va} /$ content/benedict-xv/es.html)

—Encíclica Principi apostolorum Petro, del 5 de Octubre de 1920, proclamación de San Efrén el Sirio, como doctor de la Iglesia, en $A A S$., 12 (1992), pp.459-471. Utilizamos la versión española del Centro de Estudios y Documentación Padre Hurtado, El Magisterio Pontificio. De León XIII a Benedicto XVI (Santiago, Pontificia Universidad Católica de Chile, Santiago, 2007, edición digital).

-Encíclica Sacra Propediem, 6 de enero de 1921, con ocasión del séptimo centenario de la fundación de la Tercera Orden Franciscana, en $A A S$., 13 (1921), pp. 33-41. Edición en latín, Librería Editrice Vaticana: (vatican.va/content/benedict-xv/ la.html).

—Alocución consistorial Gratum vehementer, 7 de marzo de 1921, en $A A S$., 13 (1921), pp. 121-123.

—Carta apostólica Romanorum Pontificum, del 8 de abril de 1921, en AAS., 13 (1921), pp. 372, sobre la Sociedad Jesucristo Obrero.

—Encíclica In Praeclara Summorum, 30 de abril de 1921, en el sexto centenario de la muerte de Dante Alighieri, en $A A S$., 12 (1921), pp. 209-217. Edición en latín, Librería Editrice Vaticana: (vatican.va/content/benedict-xv/la.html).

-Alocución consistorial de 13 de junio de 1921, en $A A S$., 13 (1921), pp. 281-284.

- Carta al episcopado polaco del 16 de julio de 1921, en $A A S ., 13$ (1921) pp. 424-427.

- Carta al Cardenal Kakorski y al episcopado polaco, del 16 de julio de 1921, en AAS., 13 (1921), pp. 424-427.

—Encíclica Fausto Appetente Die, 29 de junio de 1921, sobre el séptimo centenario del nacimiento de Santo Domingo, en $A A S$., 13 (1921), pp. 329-335. Edición en latín, Librería Editrice Vaticana: (vatican.va/content/benedict-xv/la.html).

-Alocución consistorial In hac quidem, del 21 de noviembre de 1921, sobre las relaciones entre la Iglesia y los Estados actuales, en $A A S$., 13 (1921), pp. 521-524. Utilizamos para la numeración y la traducción española la versión de la colección Doctrina Pontificia, II: Documentos políticos, (José Luis Gutiérrez García, BAC, Madrid, 1958).

Secretaría de Estado, Carta a José de la Torre, Presidente de la Unión Popular, 25 de febrero de 1915, en $A A S ., 7$ (1915), p. 138.

—Carta al Conde Medolago Albani, Presidente de la Unión Económico Social, 13 de agosto de 1915, en $A A S$., 7 (1915), p. 453.

Benedicto XVI, Audiencia General del 27 de abril de 2005. Edición en español, Librería Editrice Vaticana: (vatican.va/content/benedict-xvi/es.html).

- Mensaje para la celebración de la XXXIX Jornada Mundial por la Paz, del 1 de enero de 2006. Edición en español, Librería Editrice Vaticana: (vatican.va/content/ benedict-xvi/es.html).

Bibliografía general

Alvear Téllez, Julio, El Corpus Politicum de León XIII. Una interpretación anti-moderna, en Revista de Estudios Histórico-Jurídicos, 40 (2018), pp. 445-472.

Alvear Téllez, Julio, El Corpus politicum de San Pio X: una interpretación antimoderna, en Revista de Estudios Histórico-Jurídicos , 41 (2019), pp. 437-465.

Bérenger, Jean, Histoire de l'empire des Habsbourg, 1273-1918 (París, Fayard, 1990).

BLED, Jean-Paul, L'agonie d'une monarchie. Autriche-Hongrie 1914-1920 (París, Tallandier, 2014). 
Borowy, Iris, Coming to terms with world health: the League of Nations Health Organisation 1921-1946 (New York, Peter Lang, 2009).

Botrugno, Lorenzo (ed.), "Inutile strage". I cattolci e la Santa Sede nella Prima Guerra Mondiale (Ciudad del Vaticano, LEV, 2016).

Chiron, Yves, Benoit XV. Le pape de la paix (París, Pierrin, 2014).

Cooper Jr., John Milton, Reconsidering Woodrow Wilson: Progressivism, Internationalism, War, and Peace (Johns Hopkins University Press, 2008).

COOPER Jr., John Milton, Breaking the Heart of the World: Woodrow Wilson and the Fight for the League of Nations (New York, Cambridge University Press, 2001).

CorrêA de Oliverra, Plinio, Uma experiência que não deve ser esquecida, en Legionário, 599, 30 de janeiro de 1944.

D’ Abrizio, Mario, Benedetto XV, il papa della pace (Torino, Elledici, 2016).

De Dreuzy, Agnes, The Holy See and the Emergence of the Modern Middle East: Benedict XV's Diplomacy in Greater Syria (1914-1922) (The Catholic University of America Press, 2016).

Doublet, Nicholas Joseph, A politcs of peace: The Congregation for Extraordinary Ecclesiastical Affairs during the pontificate of Benedict XV (1914-1922) (Roma, Studium, 2019).

Doublet, Nicholas Joseph, Benedict XV: A Historiographical Reading (Part 1), en Melita Theologica, Journal of the Faculty of Theology University of Malta, 68/1 (2018), pp. 65-77.

ECHEVERri, Alberto, Entre la "guerra justa” y "una inútil masacre": Benedicto XV, el papa desconocido, en Theologica Xaveriana, 70 (2020): https://doi.org/10.11144/javeriana. tx70.gim

FAzo, Mariano, De Benedicto XV a Benedicto XVI (Madrid, Rialp, 2009).

FejTÖ, François, Requiem pour un empire défunt. Histoire de la destruction de l'Autriche-Hongrie (Paris, Lieu Commun, 1998).

Giovagnoli, Agostino (a cura di), Roma e Pechino: La svolta extraeuropea di Benedetto XV (Roma, Studium, 1999).

Grope, Henry E., Benedict XV: The Pope of Peace (London, The Catholic Book Club, 1940).

Hayward, Fernand, Un Pape Méconnu. Benoit XV (Tournai-Paris, Casterman, 1955).

Houlihan, Patrick J., Catholicism and the Great War: Religion and Everyday Life in Germany and Austria-Hungary, 1914-1922 (Cambridge, Cambridge University Press, 2015).

Kissinger, Henry, Orden Mundial. Reflexiones sobre el carácter de los países y el curso de la bistoria (Barcelona, Debate, 2016).

Jedin, Hubert y Repgen, Konrad, Manual de Historia de la Iglesia (Barcelona, Herder, 1984), IX.

JonHSTON, William, El genio austrobúngaro. Historia social e intelectual (1848-1938) (Oviedo, KRK Ediciones, 2009).

Letterio, Mauro, (a cura di), Benedetto XV. Profeta di pace in un mondo in crisi (Bologna, Minerva Edizioni, 2008).

Llorca, Bernardino; García-Villoslada, Ricardo et al, Historia de la Iglesia (Madrid, BAC, 1951), IV.

Marbeau, Michel, La Société des Nations (Paris, Presses Universitaires de France, 2001).

Melloni, Alberto (dir.), Benedetto XV. Papa Giacomo Della Chiesa nel mondo dell" "inutile strage" (Bologna, Il Mulino, 2017), 2 vols.

Miranda, Americo, Santa Sede e Società delle Nazioni. Benedetto XV, Pio XI e il nuovo internazionalismo cattolico (Roma, Studium, 2013). 
Ostrower, Gary, The League of Nations: From 1919-1929 (New York, Avery Publishing Group, 1996).

Paolini, Gabriele, Offensive di pace: la Santa Sede e la prima guerra mondiale (Florencia, Polistampa, 2008).

Peters, Walter H., The Life of Benedict XV (Milwaukee, The Bruce Publishing, 1959).

Petracchi, Giorgio, La Missione pontificia di soccorso alla Russia (1921-1923)”, en ValenTE, Massimilliano (a cura di), Santa Sede e Russia da Leone XIII a Pio XII (Città del Vaticano, LEV, 2009), pp. 122-180.

PolLard, John, Benedict XV: The Unknown Pope and the Pursuit of Peace (London-New York, Bloomsbury, 2000).

Regoli, Roberto y Valvo, Paolo, Tra Pio X e Benedetto XV: La diplomazia pontificia in Europa e America Latina nel 1914 (Roma, Studium, 2018).

Rumi, Giorgio (a cura di), Benedetto XV e la pace, 1918 (Brescia, Morcelliana, 1990). Rops, Daniel, Historia de la Iglesia de Cristo (Madrid, Caralt-Fayard), XII, pp. 219-226. SCHIAvon, L'Autriche-Hongrie dans la Première Guerre mondiale. La fin d'un Empire (París, Soteca, 2011).

Shine, Cormac, Papal Diplomacy by Proxy? Catholic Internationalism at the League of $\mathrm{Na}$ tions' International Committee on Intellectual Cooperation, en The Journal of Ecclesiastical History 29/4 (2018), pp. 785-805.

Schner, Juan y CÁrcel Ortí, Vicente, Benedicto XV papa de la Paz (Valencia, Edicep, 2005).

ScottÀ, Antonio, Papa Benedetto XV. La Chiesa, la grande guerra, la pace (1914-1922) (Uomini e dottrine) (Roma, Storia e Letteratura, 2009).

Trinchese, Stefano, La repubblica di Weimar e la S. Sede tra Benedetto XV e Pio XI, 19191922 (Napoli, Edizioni Scientifiche Italiane, 1998).

VARNIER, Giovanni B., 'Una guerra ingiusta". La Santa Sede e l'Italia tra neutralità e intervento (1914-1915), en Anuario de Historia de la Iglesia, 23 (2014), pp. 17-39.

-Benedetto XV e i problemi della society contemporanea, en LetTERIO, Mauro, (a cura di), Benedetto XV. Profeta di pace in un mondo in crisi, (Bologna, Minerva Edizioni, 2008), pp. 327-343.

Vinelli, Luigi, Benedetto XV costruttore di pace (Chiavari, Internòs Edizioni, 2016).

Walters, Francis Paul, A History of the League of Nations (New York, Oxford University Press, 1952), 2 vols.

Zaldívar, Pablo, Benedicto XV. Un Pontificado marcado por la Gran Guerra (Pamplona, Eunsa, 2015). 